\title{
EL PARQUE ARQUEOLÓGICO DE RECÓPOLIS (ZORITA DE LOS CANES, GUADALAJARA): TEORÍAS Y PRÁCTICAS DE UNA REALIDAD DE GESTIÓN DE NUESTRO PATRIMONIO HISTÓRICO Y MEDIOAMBIENTAL
}

\author{
Recopolis Archaeological Park (Zorita de los Canes, \\ Guadalajara): theories and practices of a reality of management \\ of our Cultural and Environmental Heritage
}

\author{
Laura María Gómez García*
}

Recibido el 14 de octubre de 2010. Aceptado el 29 de diciembre de 2010

\begin{abstract}
Resumen. Se analizan los conceptos y definiciones que dan cuerpo teórico a la Red de Parques Arqueológicos de Castilla La Mancha, exponiendo el ejemplo de gestión del Parque Arqueológico de Recópolis (Zorita de los Canes, Guadalajara). Siguiendo el recorrido histórico de esta institución se observa como se logran los objetivos de investigación, conservación y difusión de los elementos patrimoniales tanto históricos como medioambientales, así como ser motor económico social dentro de un desarrollo sostenible en la comarca en la que se asienta el Parque.

Palabras clave:Parque Arqueológico. Gestión del Patrimonio Cultural y Medioambiental. Difusión del Patrimonio. Interpretación del Patrimonio. Desarrollo sostenible.
\end{abstract}

Abstract. The concepts and definitions are discussed that give theoretical body to the archaeological parks of Castilla-La Mancha, exposing the example Recopolis (Zorita los Canes, Guadalajara) archeological park management network. Following the historical route of this institution is seen as research, conservation and dissemination of elements patrimonial both historical and environmental objectives are achieved, as well as be social economic engine of sustainable development in the region where the park sits.

Key Words: Archaeological Park. Management of the cultural and environmental heritage. Dissemination of the heritage. Interpretation of the heritage. Sustainable development.

\section{MARCO JURÍDICO Y CONCEPTO DE PARQUE ARQUEOLÓGICO}

\section{1. ¿Por qué los Parques Arqueológicos?}

El aumento del interés por todo lo relativo al Patrimonio Natural y Cultural es una constante que denota como la sociedad cada día está mejor formada e instruida y es mucho más exigente con respecto a los recursos que la rodean. Esto repercute en muchos aspectos: económicos, sociales, de valoración de los recursos, de su uso y disfrute, siendo este último relacionado con el tiempo de ocio y recreo, momento que precisamente en las sociedades modernas actuales es uno de los tiempos más valorados emocionalmente. Estos momentos de expansión cada vez más personas los completan con el enriquecimiento cultural que ofrecen el Patrimonio tanto Cultural como Natural. Y esta necesidad social debe ser satisfecha por parte de las diferentes administraciones públicas con distintos planteamientos y gestiones encauzados a un uso racional, productivo no destructivo, de ensalce y valoración, conservación y difusión de los recursos patrimoniales.

* Directora del Parque Arqueológico de Recópolis (Zorita de los Canes, Guadalajara). E-mail: Iggarcia@jccm.es 
Dentro de este contexto no sólo se empiezan a desarrollar disciplinas como la Interpretación del Patrimonio; sino que se dan distintas fórmulas de gestión y presentación de los distintos objetos patrimoniales así como se está creando todo un marco jurídico y conceptual al respecto, que se pone en práctica desde las diferentes administraciones públicas, conocedoras de estas nuevas realidades sociales vinculadas al uso y disfrute de nuestro Patrimonio en cualquiera de sus vertientes, natural o cultural.

El Estatuto de Autonomía de Castilla-La Mancha aprobado en 1982 es el punto de arranque de la gestión del Patrimonio histórico en la Comunidad Autónoma. Desde entonces y de modo exclusivo, es la Junta de Comunidades de Castilla-La Mancha quien asume las competencias de "los museos, bibliotecas, (...) de interés para la región que no sean de titularidad estatal" y "el patrimonio monumental, histórico, artístico, y arqueológico y los centros culturales de interés para la región» (Art. 31, 15-16). En menos de una década las Cortes Regionales de Castilla-La Mancha aprueban la Ley 4/1990, de 30 de mayo, del Patrimonio Histórico de Castilla La Mancha, que si bien mantiene la filosofía de la Ley 16/1985 de 25 de junio, del Patrimonio Histórico Español; se manifiesta muy novedosa al introducir que "cuando las características de los yacimientos arqueológicos así lo aconsejen, se tenderá a la creación de Parques Arqueológicos que aseguren la consolidación, recuperación y conocimiento de los yacimientos arqueológicos de Castilla-La Manchan (Artículo 18 del Título II).

Un buen ejemplo de esto es la Ley de Parques Arqueológicos de Castilla-La Mancha (Ley 4/2001, de 10-05-2001) y la creación de cinco parques arqueológicos en nuestra Comunidad: Alarcos en Ciudad Real; Carranque en Toledo; El Tolmo de Minateda en Albacete; Segóbriga en Cuenca y Recópolis en Guadalajara. Los dos primeros párrafos del Preámbulo de la Ley de Parques Arqueológicos de Castilla-La Mancha, justificativos del porqué de la misma, son el vivo ejemplo de todo lo anteriormente comentado:

En las sociedades altamente desarrolladas de nuestro tiempo se ha extendido, desde hace ya algunos años, la preocupación de los ciudadanos y de los poderes públicos por los problemas relativos a la conservación, valoración y disfrute de los bienes culturales y de la naturaleza, especialmente ante su explotación económica incontrolada y la degradación del paisaje por la acción humana; lo que ha motivado que las inquietudes al respecto, hasta hace poco limitadas a la comunidad científica, se extiendan hoy a toda la sociedad.

Nuestra Constitución ha plasmado el derecho de los ciudadanos a disfrutar de la cultura y de un medio ambiente adecuado, encomendado a los poderes públicos el deber de garantizar su conservación, la utilización racional de estos bienes y la promoción de las condiciones que faciliten su disfrute.

\section{2. ¿Qué es un Parque Arqueológico? Nacimiento del concepto}

La primera vez que detectamos el término conceptual de "Parque Arqueológico» en un organismo oficial es en la definición del concepto museo que hace el ICOM en el año 1974: "Un Museo es una Institución permanente, sin fines de lucro, al servicio de la sociedad, que adquiere, conserva, comunica y presenta con fines de estudio, educación y deleite testimonios materiales del hombre y su medion. En un párrafo posterior incluye dentro de la anterior definición a "los lugares y monumentos arqueológicos, etnográficos y naturales y los sitios y monumentos históricos, teniendo la naturaleza de un museo por sus actividades de adquisición, conservación y comunicación». Será en 1983 cuando el ICOM en la Catorce Asamblea General, amplia la definición de museos e incluye a "los parques naturales, los arqueológicos e históricos».

En 1989 en Madrid se celebra el Seminario de Parques Arqueológicos auspiciado por el Ministerio de Cultura cuyos resultados se publicaron en el año 1993. M. Ángeles Querol en su ponencia «Filosofía y Concepto de Parque Arqueológicon expuso el Plan Nacional de Parques Arqueológicos que intentó poner en marcha desde su cargo como Directora del Departamento de Arqueología del Ministerio de Cultura en 1985. Este Plan se concibió como una iniciativa de apoyo a la distintas Comunidades Autónomas para el desarrollo de actuaciones integrales en yacimientos o zonas arqueológicas de gran interés, a fin de convertirlas en áreas visitables.

\subsection{Creación de la herramienta jurídica necesaria para los Parques Arqueológicos de Castilla-La Mancha}

En el año 2001 será Castilla-La Mancha la primera Comunidad Autónoma a nivel nacional, e incluso pionera en el ámbito europeo, en procurarse un instrumento jurídico para hacer de dichos parques arqueológicos proyectos culturales, donde el visitante pueda conocer la evolución histórica de la Región y disfrutar del entorno natural. Nace así, fruto del esfuerzo realizado por un equipo de trabajo creado por la Consejería de Cultura compuesto por arqueólogos y jurídicos, la Ley 4/2001, de 10 de mayo, de Parques Arqueológicos de Castilla- La Mancha. Esta iniciativa legislativa se inspira fundamentalmente en los siguientes cuatro principios (artículo 3 de dicha Ley):

a) La protección, investigación, difusión y disfrute del patrimonio arqueológico en su entorno natural.

b) El fomento del desarrollo sostenible del ámbito geográfico y socioeconómico del Parque.

c) El impulso de una adecuada distribución de los recursos y usos del territorio, que haga a éstos compatibles con la conservación del patrimonio arqueológico y medioambiental. 


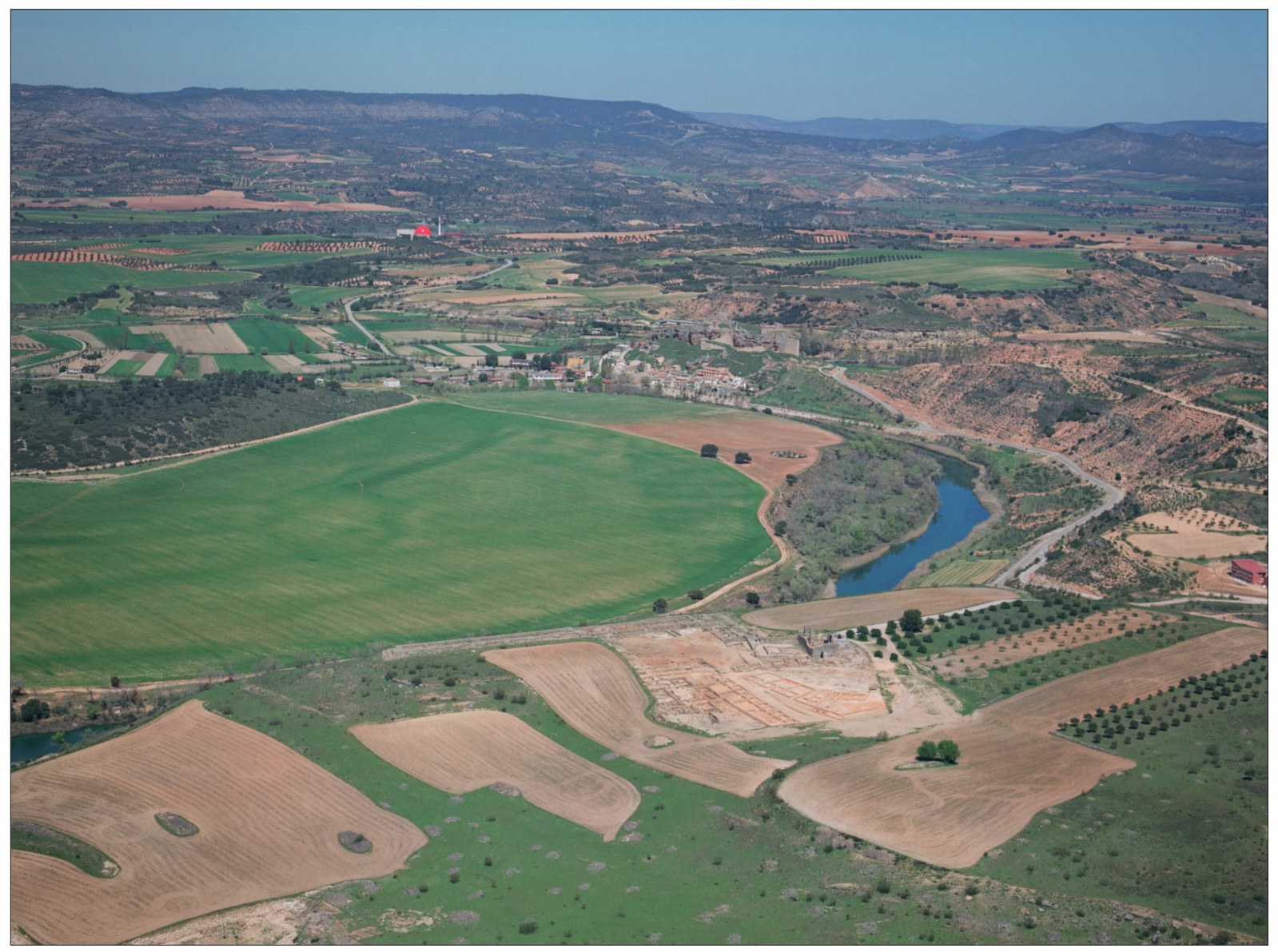

FiguRA 1. Fotografía aérea de todo el territorio que comprende el Parque Arqueológico de Recópolis.

d) La consideración del patrimonio arqueológico como un elemento esencial para el conocimiento del pasado de las civilizaciones.

Para la consecución de tales objetivos (la protección, conservación, investigación y divulgación del patrimonio cultural y medioambiental) los Parques Arqueológicos cuentan con modernos Centros de Interpretación que recogen, describen e interpretan cada uno de los elementos que forman parte de los Parques mediante una serie de servicios generales que se prestan al público visitante. Tales servicios van desde la exposición de objetos y reproducciones, paneles explicativos sobre los distintos restos y la oferta de distintos itinerarios interpretativos. Así mismo tienen cabida en sus instalaciones lugares reservados para la propia investigación arqueológica de los distintos elementos que conforman el Parque.

Según la Ley de Parques (artículo 2):

Se entiende por Parque Arqueológico el espacio físico dentro del cual, sin perjuicio de la concurrencia de otros valores culturales o naturales, confluyen necesariamente los siguientes factores:

a) La presencia de uno o varios bienes de interés cultural declarados, con categoría de Zona Arqueológica, conforme a la legislación de Patrimonio Histórico vigente. b) Unas condiciones medioambientales adecuadas para la contemplación, disfrute y comprensión públicos de las mencionadas Zonas Arqueológicas.

Atendiendo a estas condicionantes, surge la Red de Parques Arqueológicos de Castilla-La Mancha, uno por cada provincia y cada uno con su propio Decreto Ley de Creación. La declaración del Parque Arqueológico de Recópolis la encontramos en el Decreto 280/2004, de 30-11-2004.

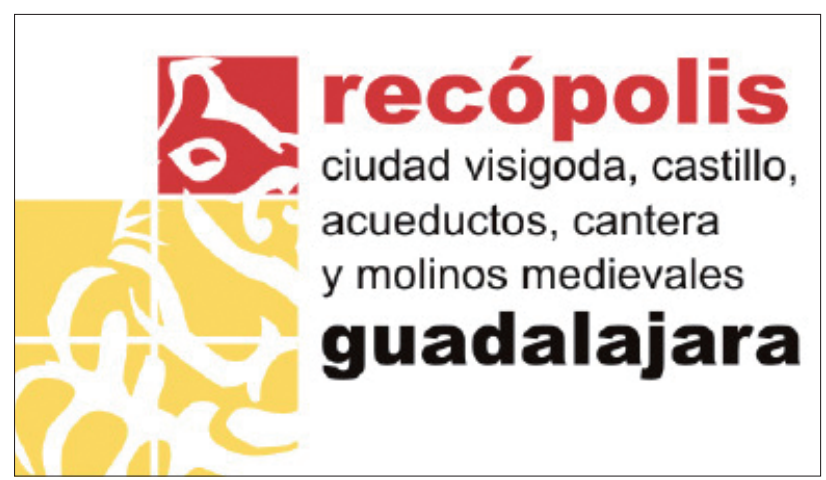

FIgura 2. Al igual que el PAR, cada Parque Arqueológico tiene su propio distintivo o logotipo que le caracteriza e imprime imagen propia, aunque todos son y forman la Red de Parques Arqueológicos de Castilla-La Mancha. 


\section{PARQUE ARQUEOLÓGICO DE RECÓPOLIS (ZORITA DE LOS CANES, GUADALAJARA): ELEMENTOS QUE LO CONFORMAN}

El Parque Arqueológico de Recópolis (Guadalajara) está formado por una serie de yacimientos arqueológicos que nos llevan por un recorrido histórico que comienza en la época visigoda, pasando por la andalusí y feudal, inscritos en un entorno natural de enorme impacto por su belleza, y de relevante importancia medioambiental para la conservación de fauna y flora de especial interés, lo cual da como resultado un recorrido excepcional por un paisaje histórico que se hace entendible en función de las distintas transformaciones que ha sufrido con el devenir de las distintas culturas que lo han habitado.

\subsection{Recursos culturales y arqueológicos del PAR}

\subsubsection{Yacimiento arqueológico de Recópolis}

Ciudad visigoda fundada por el rey Leovigildo en el año 578 en honor a su hijo Recaredo. Este yacimiento tiene la característica e importancia histórica de ser la única ciudad de nueva planta fundada en todo el occidente europeo así como de constituir uno de los pocos núcleos urbanos que la cultura visigoda nos ha legado. La actividad urbana se desarrollo entre finales del siglo $\mathrm{VI}$ y comienzos del siglo IX, siendo un importante centro administrativo, político y económico. Su emplazamiento responde a factores estratégicos y viarios, localizándose en un cruce de caminos. De entre los restos documentados en los trabajos de excavaciones sistemáticas dirigidas por el Dr. Lauro Olmo Enciso, destacan la muralla que rodea el núcleo urbano así como el conjunto palatino, compuesto por un edificio administrativo de planta rectangular y una iglesia de planta de cruz latina adosada al mismo. También destacan los restos de una puerta monumental que daba acceso al conjunto palatino; $y$ dos edificios sitos en la calle principal dedicados a actividades comerciales y artesanas (figs. 3 , 4 y 5$)$.

\subsubsection{Castillo de Zorita de los Canes}

Está en una situación de excelencia estratégica desde donde se controla uno de los pasos del río Tajo, así como los valles del Henares a las Sierras de Cuenca que son paso hacia Levante, junto a la confluencia de distintos ecosistemas (Alcarria-La

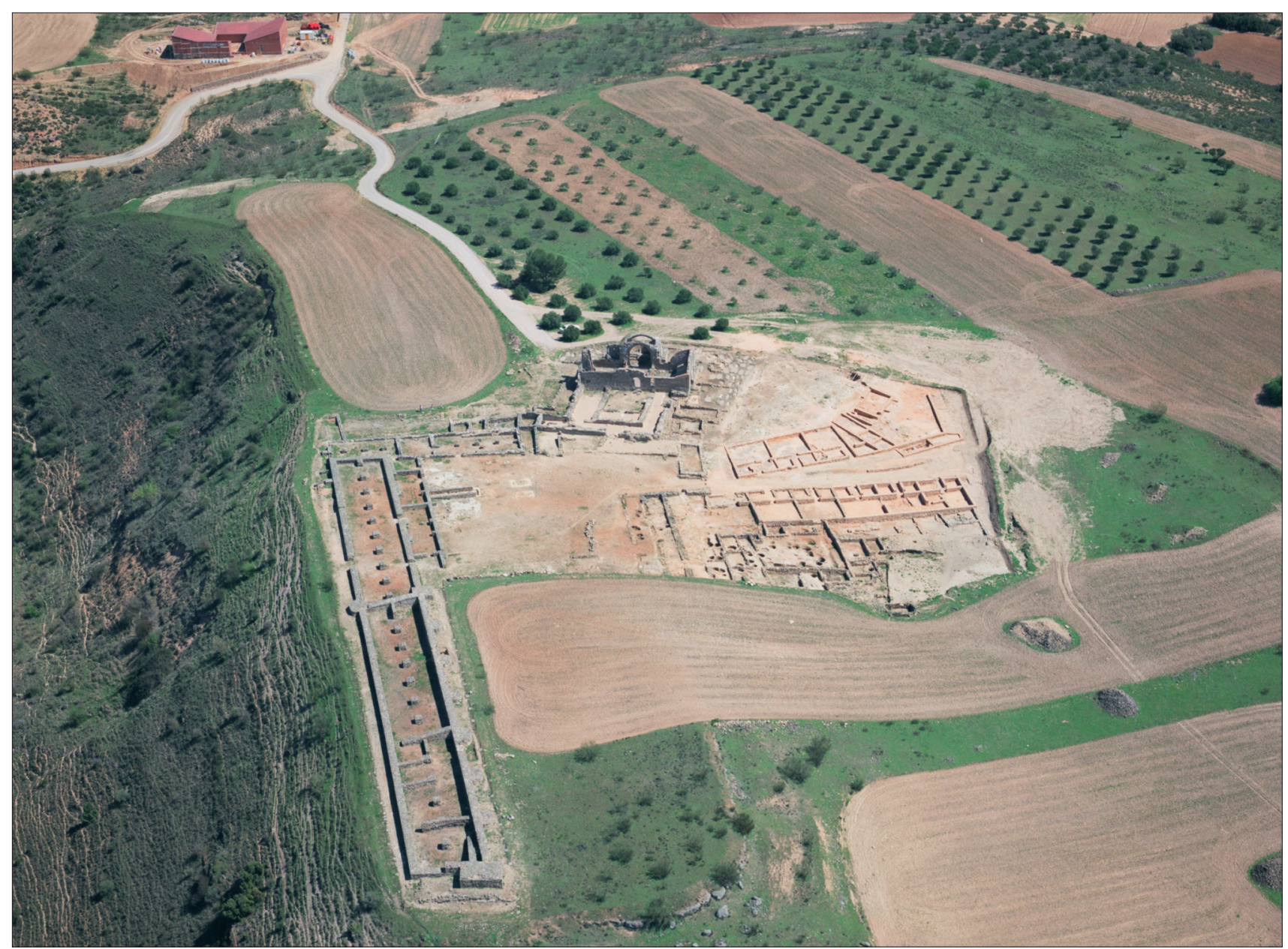

FigURA 3. Vista aérea del yacimiento arqueológico visitable Recópolis. 


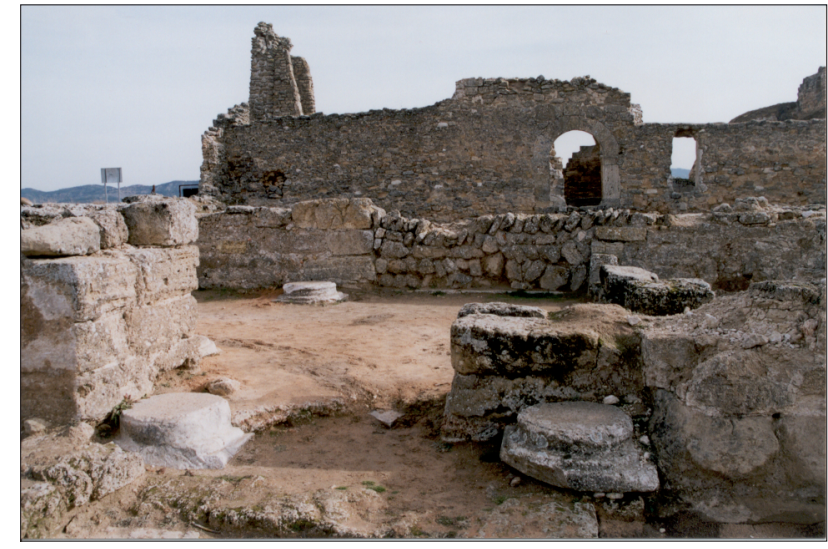

FIGURA 4. Imagen de la puerta de acceso al nartex de la basílica visigoda de Recópolis.

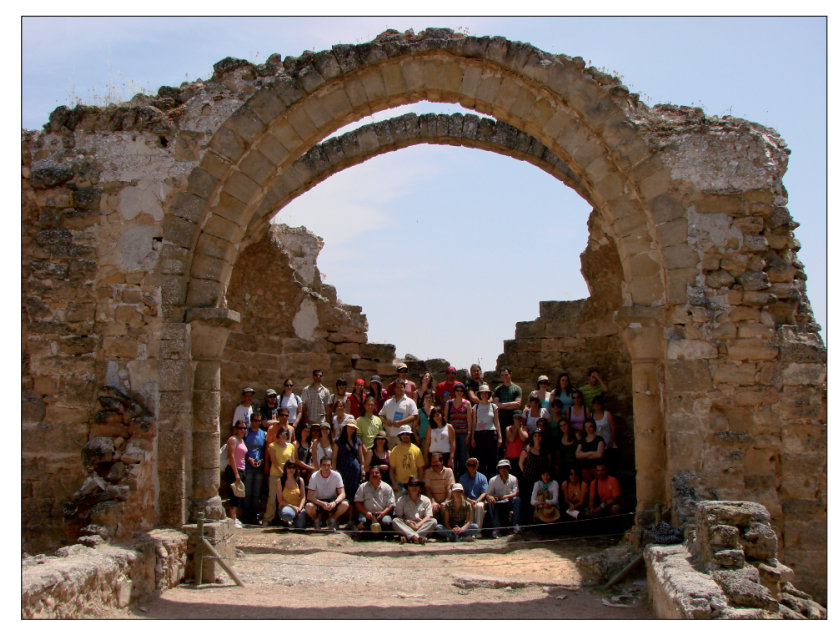

FIGURA 5. Detalle del interior de la basílica visigoda con un grupo de excursionistas posando.

Mancha) lo que explica también su gran importancia histórica. Fue fundado por Muhammad I a mediados del siglo IX. Al presentar diferentes modos de aparejo se aprecian las distintas fases constructivas de época islámica dándose el verdadero desarrollo del castillo en época califal. Con la llegada de la Orden de Calatrava en los siglos XIII y XIV se desarrollan también importantes obras de arquitectura e ingeniería, destacando de este período la iglesia que preside el castillo de estilo protogótico con una única nave (figs. 6, 7 y 8).

Esta alcazaba islámica primero y luego fortaleza de la Orden de Calatrava, es reflejo del dinamismo cultural que se aprecia en este territorio $y$, obviamente, también es el otro gran yacimiento arqueológico del Parque. En la actualidad no es visitable, pues acaban de finalizar las tareas de restauración y consolidación de los paramentos del castillo llevadas a cabo gracias al 1\% Cultural que el Ministerio de Fomento y la Junta de Comunidades de Castilla La Mancha han adjudicado para su rehabilitación. En estos momentos desde el Parque Arqueológico se están llevando a cabo tareas de limpieza y reacondicionamiento para que prontamente sea yacimiento visitable (figs. 9 y 10).

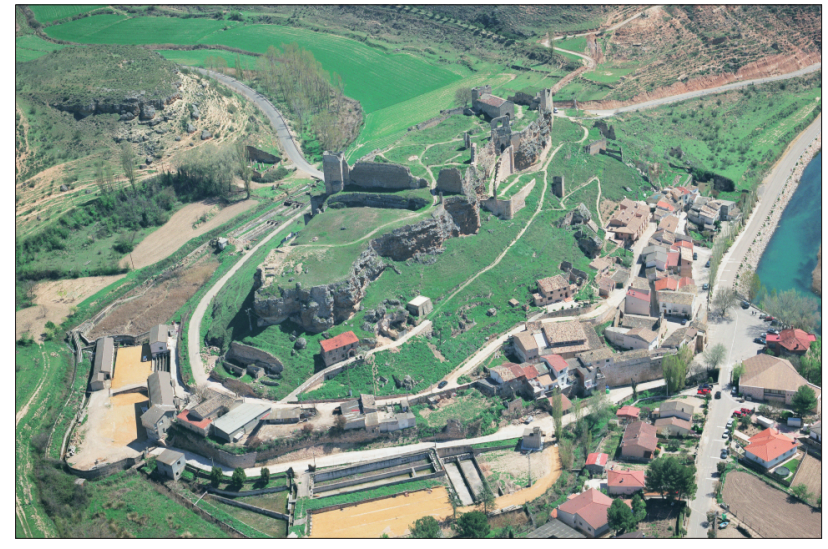

FiguRA 6. Vista aérea del Castillo de Zorita de los Canes.

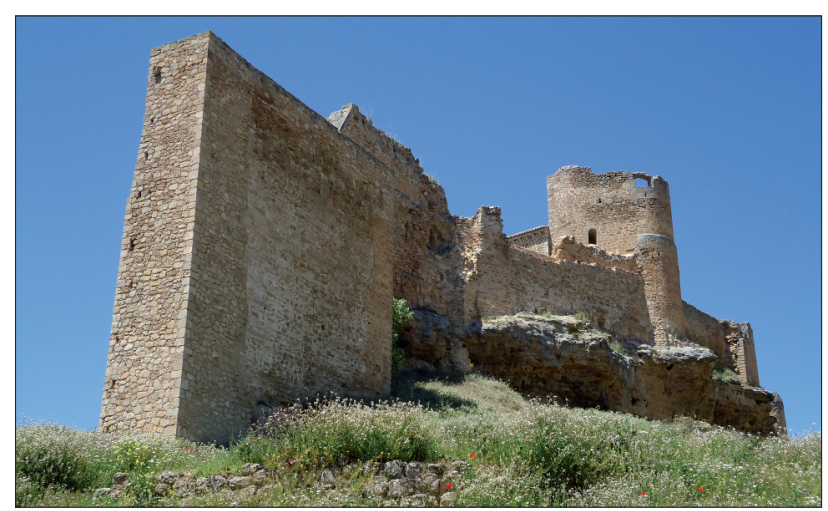

FIGURA 7. El enclave sobre el promontorio de arenisca confiere a la alcazaba un alto grado de inexpugnabilidad, característica elocuente de este BIC.

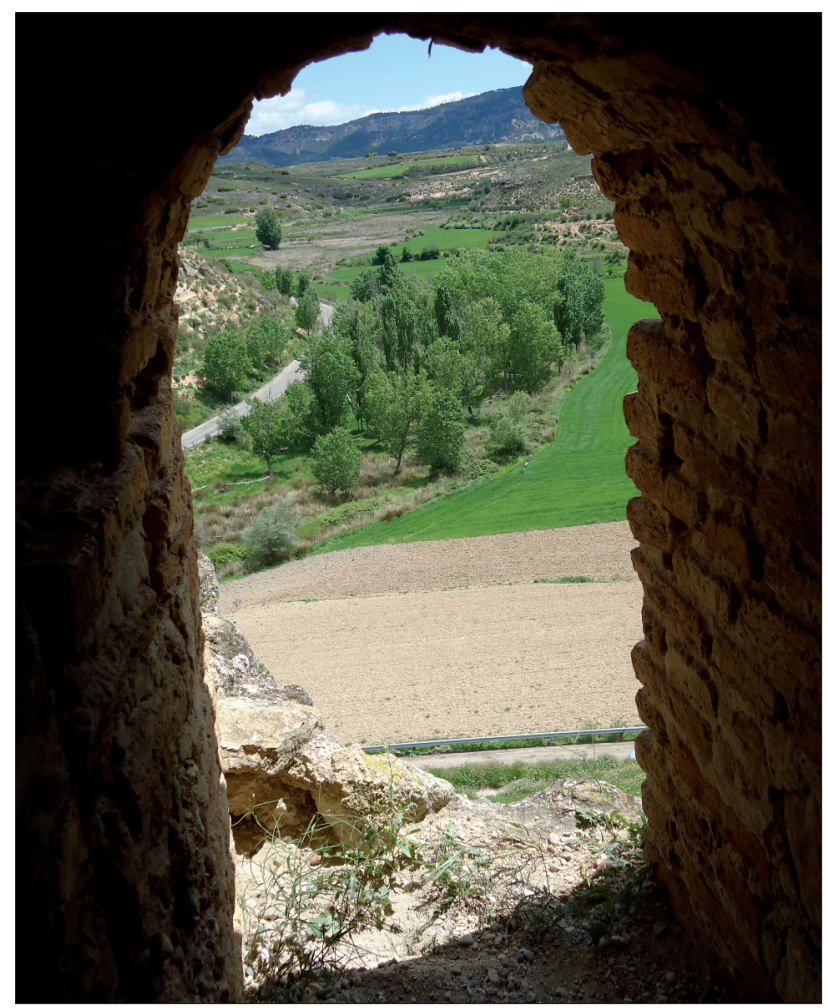

FIGURA 8. El control estratégico de los valles que dominan el territorio es patente desde el castillo. 


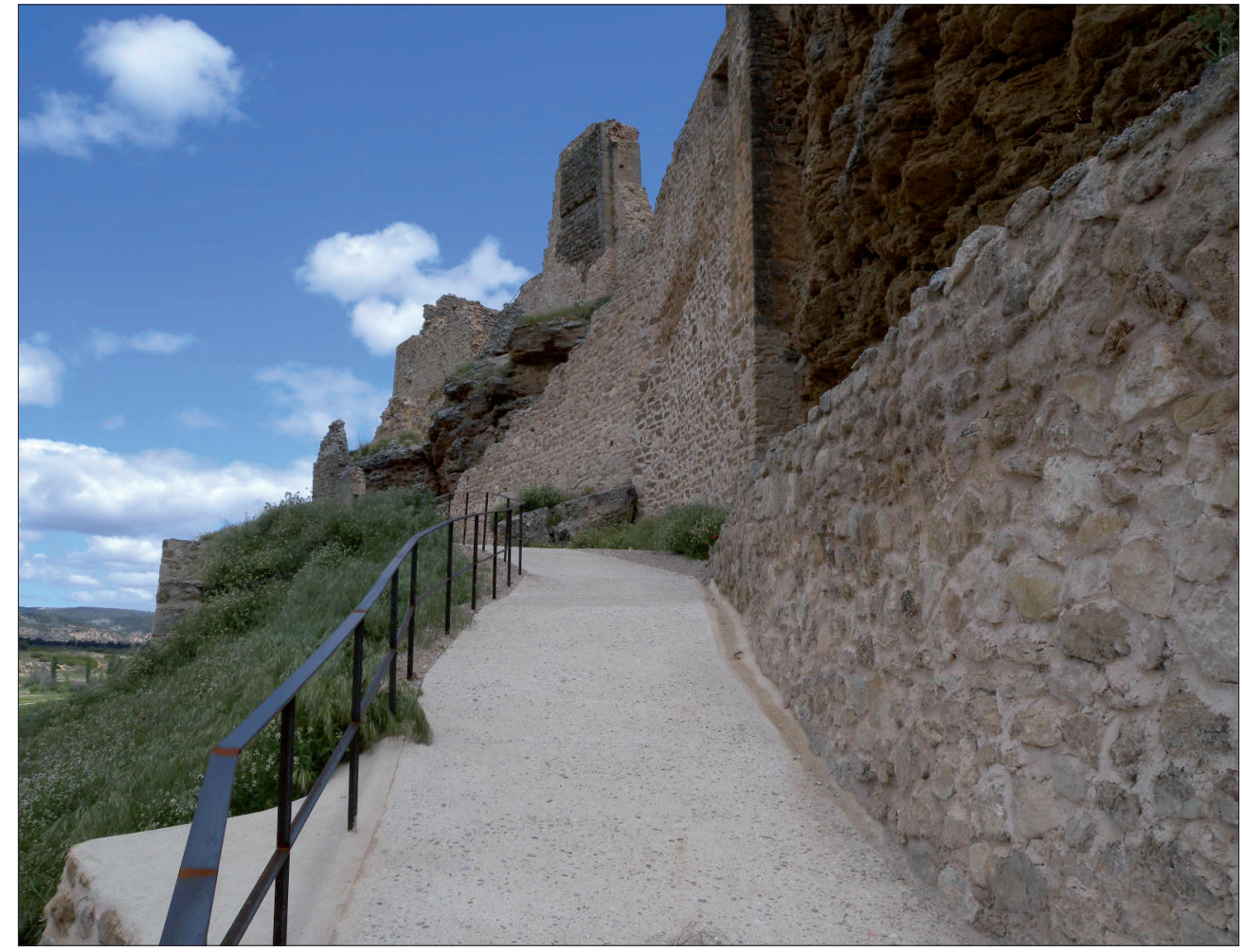

FiguRA 9. Ejemplo de acondicionamiento de los accesos al Castillo de Zorita en la rehabilitación realizada por el Ayuntamiento de Zorita de los Canes y llevada a cabo con la colaboración del Ministerio de Fomento y la Junta de Comunidades de Castilla-La Mancha con cargo a los Planes y Programas para la conservación del Patrimonio Arquitectónico e Histórico "1\% Cultural" finalizada en abril de 2010.

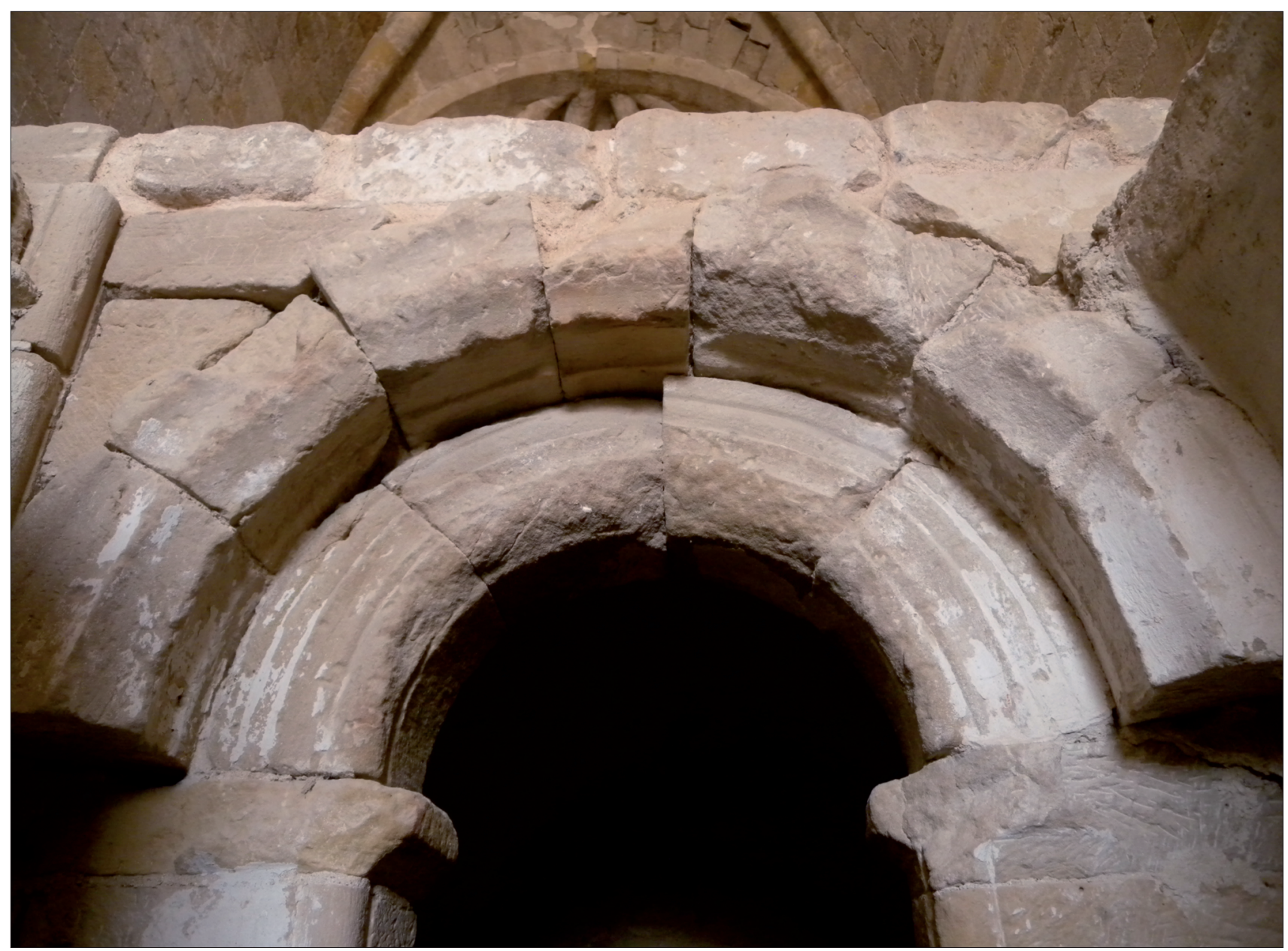

FiguRA 10. Arcos de medio punto de la entrada a la cripta de iglesia calatrava del Castillo de Zorita. 
FiguRA 11. Puerta de acceso a la muralla de Zorita de los Canes, y por ende, a la alcazaba.

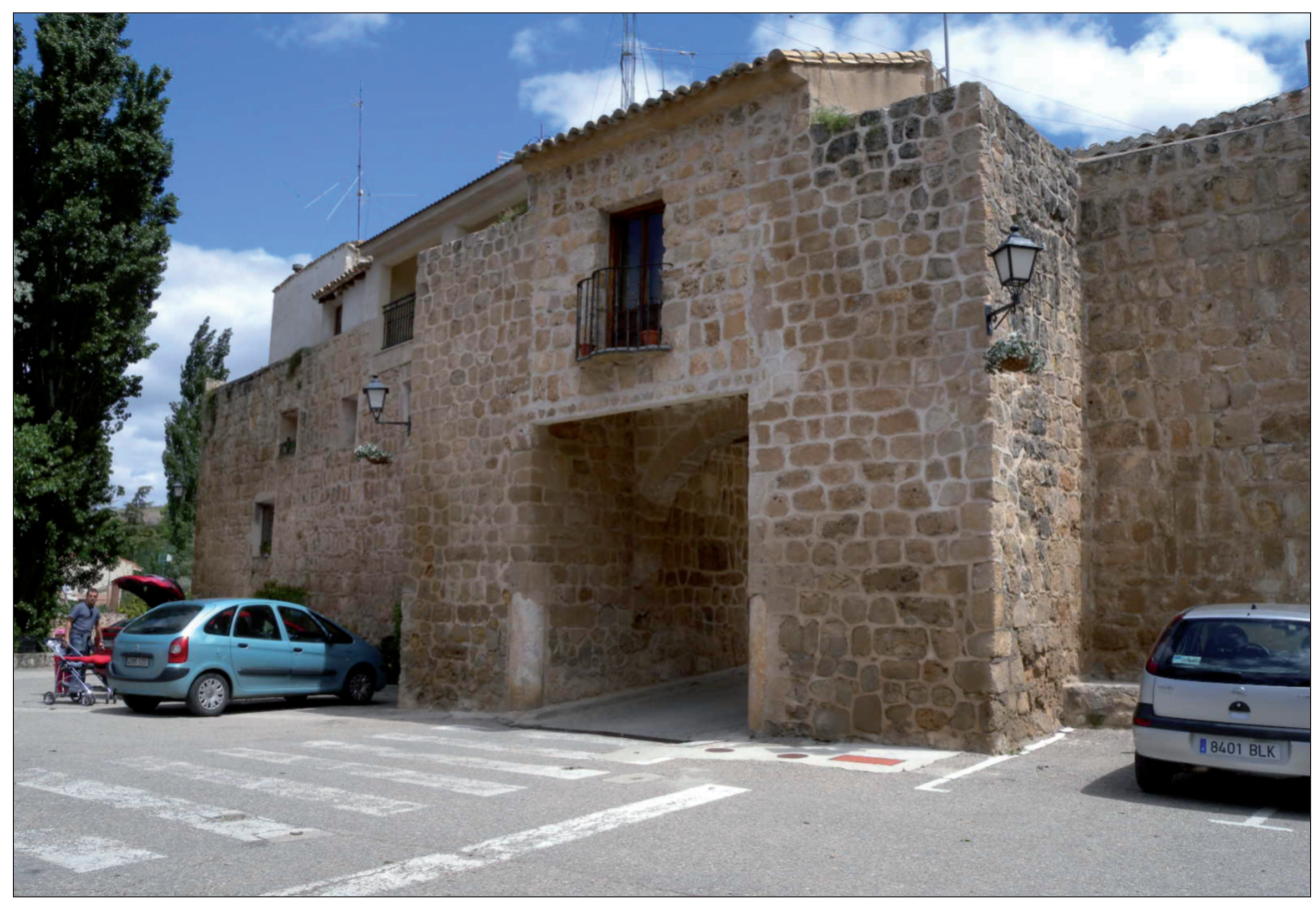

\subsubsection{Murallas de Zorita}

Construidas en el siglo $X$ forman parte de la ampliación de época califal, como podemos observar por su técnica constructiva. Se conservan buena parte de ellas, que todavia siguen constituyéndose como límite perimetral del municipio y es destacable el arco de entrada (fig. 11).

\subsubsection{Molino de la Condesa y Acequias}

Situado en el paraje denominado Los Palacios fuera del casco urbano de Zorita, su importancia estriba en el mantenimiento de una estructura de regadío con origen en tiempos medievales.

Los Fueros de la Villa mencionan en varias ocasiones los molinos que poseía el territorio de Zorita, lo que subraya su importancia dentro del sistema productivo. En este caso, nos encontramos ante una edificación que conserva gran parte de sus elementos estructurales (acequias, rueda de molino, cantera de donde se extraían las mismas) en un paraje natural de gran belleza. La interacción del castillo y del molino es clara si tenemos en cuenta que las acequias que salen de éste son las que alimentaban la huerta del arroyo Badujo y entraban en el castillo por su parte más oriental, mientras que otro ramal alimentaba las huertas próximas al Tajo.

Este molino del Valle Badujo está recogido en Carta Arqueológica con una descripción de lugar de explotación, producción y comercio, con una cronología del s. VIII d. C.-s. XV.

Por otro lado hemos localizado en las Relaciones Topográficas de Felipe I/ de 1575, en la parte dedicada a la Villa de Zorita, en el vigésimo segundo capítulo, una descripción del lugar, su fecha de construcción y usos de este molino que nos ocupa:

(...), y en el río de badujo la dicha Villa de Zorita habrá como doce o trece años que la dicha Villa y el Concejo de ella edificó un molino harinero en el dicho río, y que sobre ella el Concejo de Almonacir trató pleito con el Concejo de esta Villa sobre el dicho molino, y que la renta que solia rentar es del Concejo de Zorita y no de otras personas, y en todo el verano, como es desde el mes de Marzo hasta el mes de Septiembre, el dicho molino no muele, ni puede moler porque se toma el agua para las heredades que dicho es ya.

De esta relación se pueden entresacar unos datos concretos: en primer lugar, que es una construcción del siglo XVI, en concreto del año 1562. Por otro lado, su construcción se debe al Concejo de la propia villa, y que dicho Concejo es el dueño de las rentas de este molino harinero. Así mismo, se describe la cuestión del parón de la molienda durante los meses de verano, hecho que se justifica para los regadíos de las tierras, hecho que además se constata en los propios restos que nos quedan del molino, pues se observan todo un sistema de acequias destinadas al riego de las parcelas aledañas. Acequias de las cuales muchas, hoy en día, siguen en funcionamiento.

\subsubsection{Necrópolis de la Peña de los Pavos}

Conjunto de enterramientos, que por su tipología y orientación deben considerarse cristianos. A pesar de que no han aparecido restos óseos de importancia, la presencia de material cerámico nos índica una fecha aproximada que se sitúa entre los siglos XIII y XIV. 


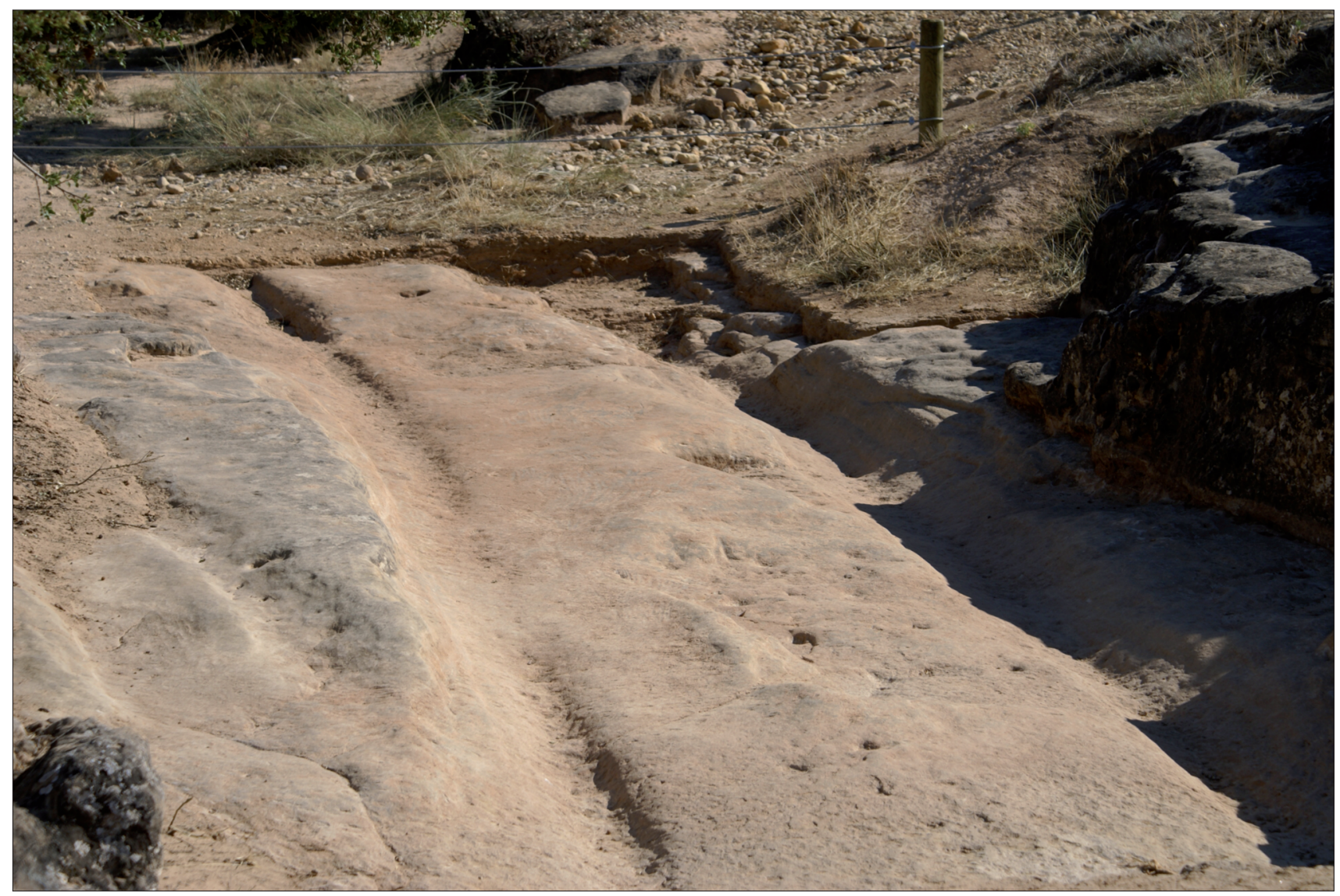

FIGURA 12. Rodadas de carro en el denominado "Camino Medieval» de Recópolis.

\subsubsection{Necrópolis de la Crucetilla}

Conjunto de enterramientos, localizados en el cerro de este nombre que por su tipología y orientación se adscriben a época islámica.

\subsubsection{Camino Medieval}

A lo largo del camino natural y tradicional de conexión entre Recópolis y el Castillo de Zorita hay restos de rodadas de carro en las afloraciones de arenisca; así como las cárcavas de extracción de piedra para el encajonamiento del camino en dichas afloraciones cuyos materiales fueron también aprovechados para la talla de sillares para la construcción de los edificios más emblemáticos de la ciudad visigoda. En algunos tramos incluso se pueden observar los agujeros de los postes de sujeción de los artificios para la carga de dichos sillares sobre los carros de transporte (fig. 12).

\subsubsection{Otros elementos arqueológicos relacionados con Recópolis}

Son las canteras y el acueducto. Hay varias canteras localizadas en las proximidades de la ciudad de donde se ex- trajeron los sillares para la construcción de los edificios notables de la misma.

El acueducto captaba el agua de una zona de manantiales situada aproximadamente a $2 \mathrm{kms}$. de la ciudad, en dirección SE, en la Sierra de Altamira.

\subsection{Recursos medioambientales y paisajísticos del PAR}

El Parque Arqueológico de Recópolis se encuentra rodeado de tres grandes espacios naturales con distintos tipos de protección tanto autonómicos como europeos. Estos espacios son la Sierra de Altomira, la Reserva Fluvial de los Sotos del Río Tajo y la Microreserva de los Cerros Margosos de Pastrana y Yebra. Desde el PAR se hace especial hincapié en la importancia de la conservación de estos espacios como refugio de fauna y conservación de flora de especial interés.

\subsubsection{La Sierra de Altamira}

Espacio protegido a nivel de la Unión Europea como Lugar de Interés Comunitario (LIC) y Zona de Especial Protección para las Aves (ZEPA) dentro de la Red Natura 2000 (Red 


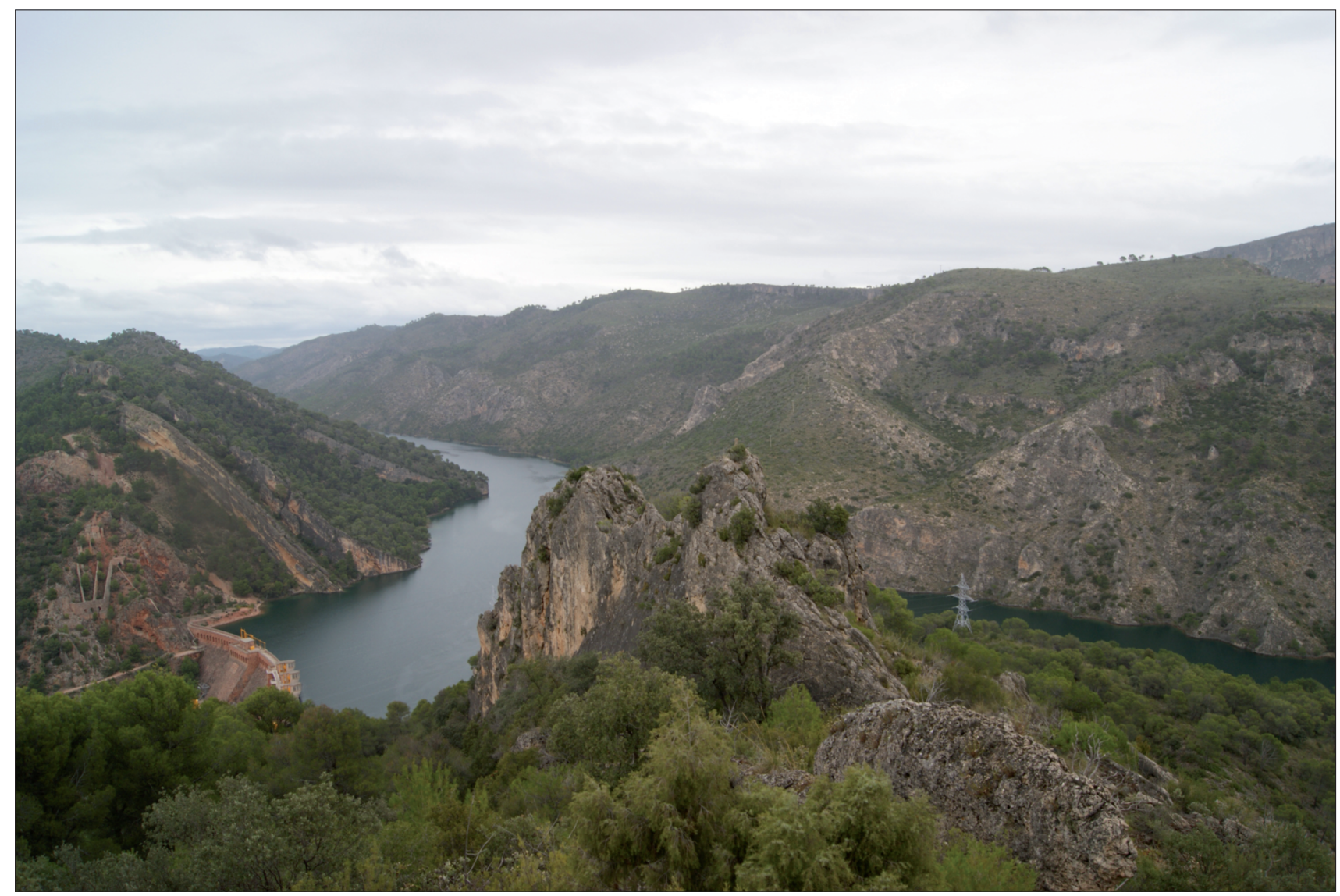

FIguRA 13. Vista panorámica de la Sierra de Altamira, con detalle de la Presa de Bolarque y el Río Tajo.

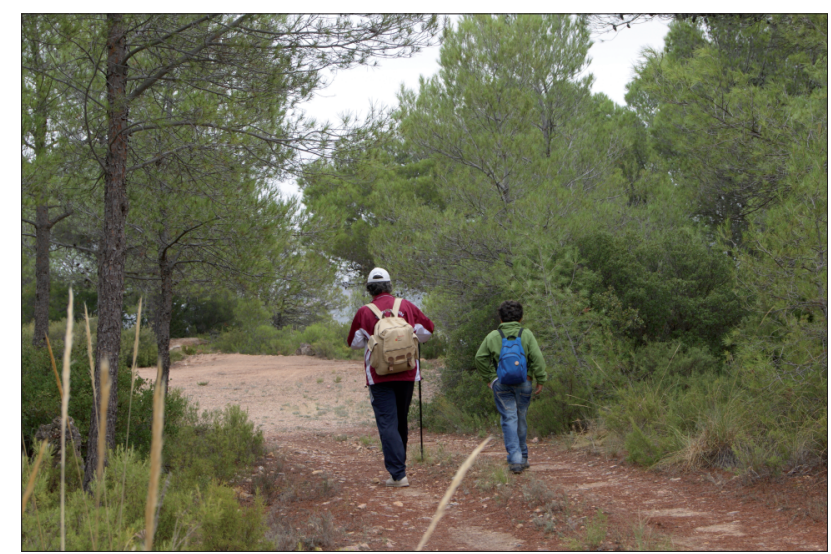

FigURA 14. Son numerosas las rutas de senderismo en esta estribación montañosa para uso y disfrute de los amantes de la Naturaleza.

Europea de Espacios Naturales de alto valor ecológico donde se establecen áreas de conservación de la biodiversidad) debido a su alto valor ecológico y paisajístico. Consta de Zonas Especiales de Conservación designadas de acuerdo con la Directiva Hábitat, así como de Zonas de Especial Protección para las Aves establecidas en virtud de la Directiva Aves. La finalidad de esta Red es asegurar la supervivencia a largo plazo de las especies y los hábitats más amenazados de Europa, contribuyendo a detener la pérdida de biodiversidad ocasionada por el impacto adverso de las actividades humanas. Esta Red es el principal instrumento para la conservación de la naturaleza en la Unión Europea (figs. 13 y 14).

La Sierra de Altamira se prolonga durante $125 \mathrm{~km}$ con dirección N-S siendo una alineación montañosa de naturaleza calco-dolomítica cretácica que ha servido como corredor ecológico para numerosas especies de flora y fauna. Además debemos mencionar que el embalse de Bolarque, que se encuentra encajado en esta formación geológica, fue declarado Refugio de Fauna en 2001 por el gran numero de aves que alberga en época migratoria (aproximadamente unas 2.451 de 20 especies distintas, entre ellas algunas tan importantes como el zampullín chico o el ánade friso).

En la Sierra de Altamira se pueden encontrar hasta 45 tipos de aves distintas de gran importancia, la mayoría de ellas están incluidas en el Catalogo Regional de Especies Amenazadas de Castilla-La Mancha (Decreto 33/1998). Las aves encuentran aquí un lugar idóneo para la cría y la supervivencia debido a que aprovechan los amplios valles como zona de campeo para conseguir alimento y los roquedos y paredes abruptas las aíslan de posibles impactos que puedan afectarles. 


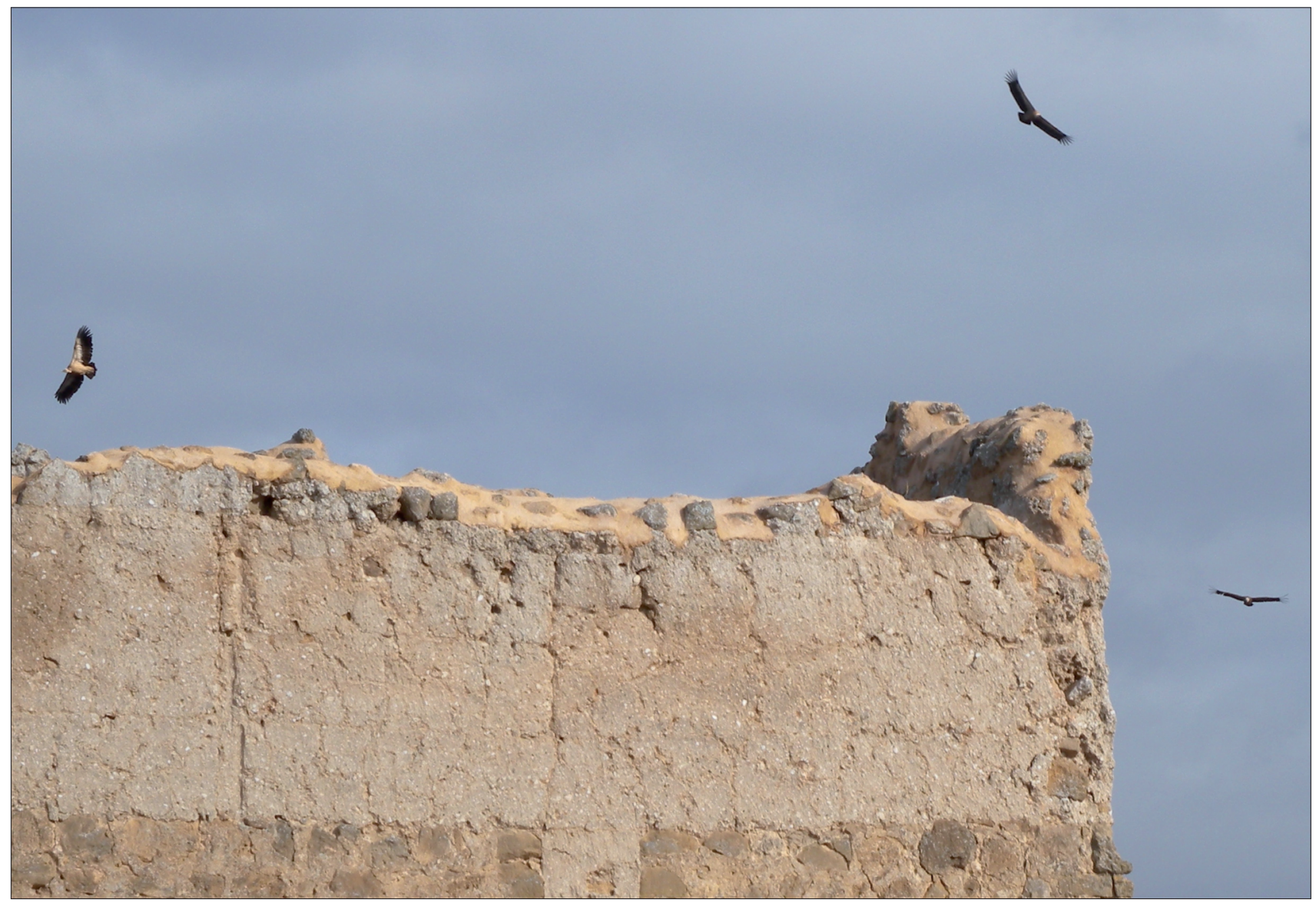

FIGURA 15. Grupo de buitres leonados surcando los cielos del PAR. Son imágenes habituales en este territorio.

Las especies de más interés son el grupo de las rapaces, pudiéndose observar ejemplares de Águila perdicera (Hyeratus fasciatus) muy amenazada; Águila real (Aquila chrysaetos); Halcón peregrino (Falco peregrinus); Buitre leonado (Gyps fulvus); Alimoche (Neophron pernocterus); Águila culebrera (Circaetus gallicus); Águila calzada (Hieratus pennatus); Cernícalo primilla (Falco naumanni); Aguilucho lagunero (Circus aeruginosus), Ratonero común (Buteo buteo) (fig. 15).

Además de las rapaces mencionadas se pueden ver aves acuáticas y zancudas también muy abundantes por esta zona debido principalmente a los embalses que rodean al Parque Arqueológico como también al río Tajo, protegido en este tramo con la figura de Reserva Fluvial e incluida en la ZEPA Sierra de Altomira. Las especies de avifauna que se pueden observar son el Cormorán, la Garza Real, Garza Imperial, Somormujos, Garcilla, Azulón, Porrón, Focha común, Silbón europeo, Pato cuchara.

También hay que destacar algunas especies de mamiferos que campean por estos valles como el corzo, el jabalí, el tejón o el zorrillo.

Desde el punto de vista vegetal también encontramos sorpresas, pues en la Sierra de Altamira entre los encinares, coscojares y quejigares destacan dos especies paradigmáticas y bien diferentes como son el madroño (Arbutus unedo) propia del sector manchego y el cambrón (Genista pumila sbs. mugonensis) más propia del sector levantino. Esta convivencia tan sorprendente se debe a que ésta es la última Sierra que el Sistema Ibérico tiende hacia la Mancha y por ello es una zona de transición, albergando ambas especies vegetales.

\subsubsection{La Reserva Fluvial de los Sotos del Río Tajo (Decreto 288/2008 de 7 octubre de 2003)}

La cuenca del río Tajo en la provincia de Guadalajara baña 270 municipios de los 288 que la forman. El río Tajo cuyo nombre hace referencia a las profundas gargantas y cañones cuya forma de $V$ asemeja a los "tajos» que abriría una imaginaria espada en la Tierra, tiene una superficie de $1.149 \mathrm{~km}^{2}$ (en la Alcarria). Es el río principal de la comarca, aparece represado en tres grandes embalses hiperanuales a lo largo de la Alcarria: Entrepeñas-Buendía con capacidad máxima de $835 \mathrm{hm}^{3}$, Bolarque con $31 \mathrm{hm}^{3}$ y la Bujeda con 7 $\mathrm{hm}^{3}$. A este conjunto se le denomina coloquialmente "Mar de Castilla", y constituye el principio del Trasvase Tajo-Segura. Además, el Tajo en su recorrido por la Baja Alcarria que- 


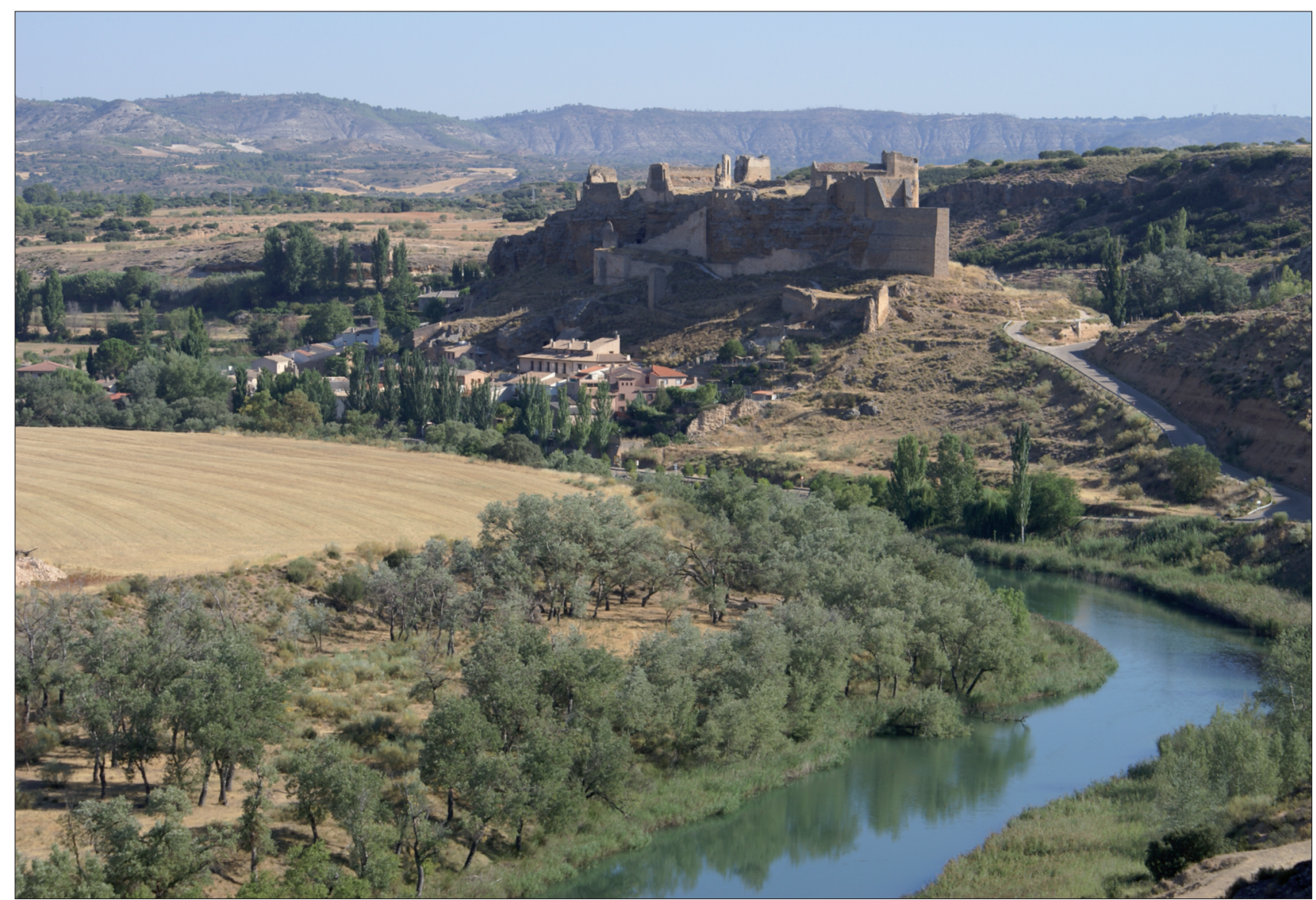

FIGURA 16. El río Tajo es el indiscutible protagonista del paisaje histórico del Parque.

da retenido en dos ocasiones más para el aprovechamiento hidroeléctrico en los pequeños embalses de Zorita $\left(3 \mathrm{hm}^{3}\right)$ y Almoguera $\left(7 \mathrm{hm}^{3}\right)$, (fig. 16).

En cuanto a los valores naturales de este espacio hay destacar sin duda las galerías fluviales arbóreas que son más bien escasas debido a la actividad agrícola, principalmente. Son fundamentalmente alamedas, mimbreras y saucedas que acompañan al río en su viaje hasta la desembocadura. Ante la evidente amenaza e importancia de estas comunidades riparias se declaró a través del Decreto 288/2003 de 7 de octubre, la Reserva Fluvial Sotos del río Tajo en los términos municipales de Zorita de los Canes, Pastrana y Yebra con una superficie de 121.31 ha. dado que, precisamente, en este tramo del río las galerías fluviales arbóreas están muy bien conservadas, y en absoluto deforestadas.

Con respecto a la ictiofauna que encontramos en este ecosistema mencionar el Barbo comiza (Barbus comiza) endemismo ibérico, prefiere aguas con poca corriente y abundante vegetación actualmente bastante amenazado debido a la contaminación de las aguas y Boga del Tajo (Chondostroma polylepis) también endemismo ibérico, es utilizado como indicador de alta calidad de aguas de río.

Tan destacable es la importancia cultural que el río Tajo tuvo en los antiguos asentamientos humanos como re- curso natural que aportaba agua y alimento a través de las huertas, así como vehículo hacia Toledo de las embarcaciones y sobre todo de la madera de los árboles talados a lo largo del recorrido, trabajo de los famosos gancheros (fig. 17).

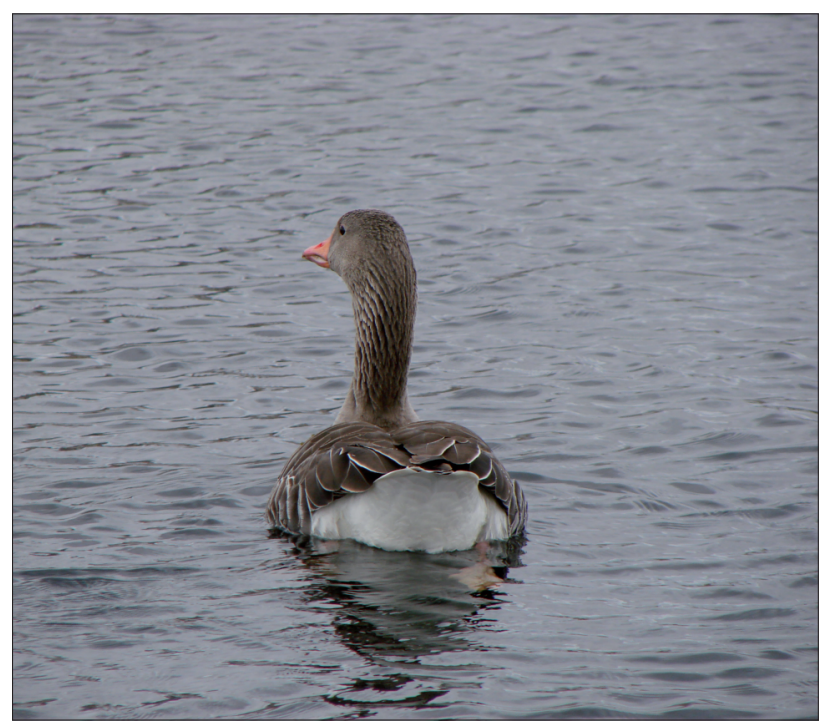

Figura 17. Es muy probable poder observar desde el PAR toda clase de aves acuáticas dado el gran número tanto de especies como de individuos que habitan este tramo del Río Tajo. 


\subsubsection{La Microreserva de los Cerros Margosos de Pastrana y Yebra (Decreto 70/2002 del 14 de mayo)}

Esta unidad está formada por materiales blandos como son arcillas, yesos o margas, esto da lugar a un paisaje blanquecino y grisáceo de topografía ondulada. El yeso es tóxico para la mayoría de las plantas y la escasa disponibilidad de agua hace que en esta unidad aparezca una vegetación característica de tipo gipsícola y xerofítica de distribución restringida. Es aquí donde aparecen las únicas poblaciones conocidas en el mundo de Limonium Erectum, endemismo de la provincia de Guadalajara e incluida en el Catálogo Regional de Especies Amenazadas como en peligro de extinción. Debido a la presencia de esta especie junto con Gypsophila bermejo o Lepidium cardamine en el año 2002 queda protegido este espacio a través del Decreto 70/2002 del 14 de mayo con la figura de Microreserva.

\section{DE LA INTERPRETACION DEL PATRIMONIO Y SU MARCO TEÓRICO}

Estamos ante una disciplina que, si bien ya está plenamente consolidada en los países anglosajones y en parte de Latinoamérica y algunos países de la Unión Europea, en nuestras latitudes empezamos a conocer hace tan sólo poco más o menos dos décadas. En estos primeros albores se hablaba de
Interpretación Ambiental puesto que esta herramienta de comunicación estaba vinculada en origen a la programación de procedimientos para la transmisión de mensajes relacionados con el Patrimonio Natural. Prontamente se verá como este método de aproximación y comunicación es aplicable al desarrollo de todo un discurso y soporte técnico de comprensión del Patrimonio Histórico y Cultural y ya, desde la década de los '90 del siglo pasado, se habla de un modo más globalizador de Interpretación de Patrimonio, entendiendo que éste pueda ser tanto Natural como Patrimonial.

Poco a poco se han dado en nuestro país diferentes eventos teniendo por protagonista a esta disciplina con los que, a su vez, se ha ido generando todo un marco teórico, como por ejemplo el IV Congreso Internacional sobre Interpretación del Patrimonio (org. por Heritage Interpretation International, Barcelona 1995); así como también la creación de distintas asociaciones de distinto carácter, como por ejemplo la Asociación para la Interpretación del Patrimonio (AIP-España) que tiene carácter nacional (Guerra, 1998a, b y c; Guerra y Morales, 1987 y 1996; Morales, 1997 y 2001), (fig. 18).

Según, precisamente, la AIP, la Interpretación del Patrimonio es «el arte de revelar in situ el significado del legado natural, cultural o histórico, al público que visita esos lugares en su tiempo de ocion. Esta definición nos aproxima no sólo a la esencia misma de la Interpretación del Patrimonio (IP), sino que matiza ciertos sustantivos dotándoles así de

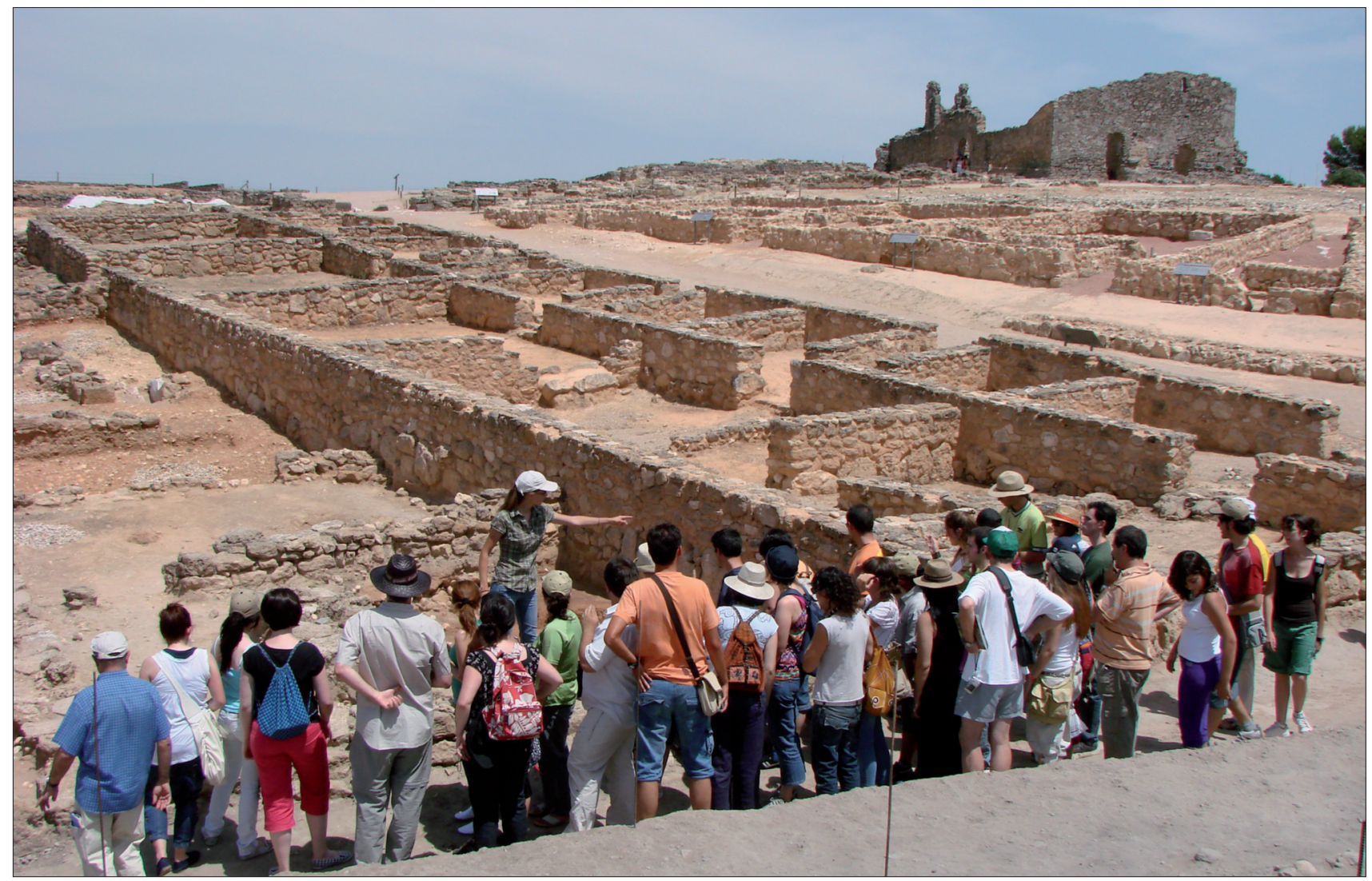

FIGURA 18. Grupo de visitantes en el yacimiento arqueológico de Recópolis. 
unas características concretas que son definitorias en todo este proceso. Por ejemplo el público, destinatario del la interpretación, está constituido exclusivamente en esta definición por un público general que representa una audiencia no cautiva que no está sujeta a ningún tipo de obligación cuando se enfrenta a un bien cultural o natural y cuya expectativa de provecho es de carácter meramente contemplativo y espiritual sin existir ningún tipo de incentivo extraordinario como pueda resultar ser aprobar exámenes, recibir algún punto por un trabajo determinado, etc. Esta característica de audiencia no cautiva viene marcada fundamentalmente por momento en el que realizan dichas actividades: su tiempo de ocio. Pero si bien este no es el caso de los grupos escolares que pueden acudir a visitar un espacio protegido en calidad de alumnado acompañado de los docentes y con objetivos marcados por distintos curricula educativos a los que se tengan que someter, luego no se les pueda catalogar de "audiencia no cautiva», pues precisamente lo es. Aunque tampoco podemos dejar de considerarles público potencial de una visita interpretativa, puesto que su visita lleva como objetivo principal el conocer el espacio natural o cultural que competa, luego pueden emplearse perfectamente las técnicas interpretativas en el tratamiento de este tipo de colectivo, así como de otras comunidades similares. La interpretación busca despertar la curiosidad por encima de satisfacerla y es este pequeño detalle el que marca la diferencia sustancial entre lo interpretativo y lo estrictamente educativo (Guerra, 1998); luego lo estrictamente educativo puede utilizar esta técnica como herramienta para la consecución de unos objetivos de estricto carácter educativo de aprehensión de conceptos claves de determinados conocimientos.

Otra constante a tener en cuenta, dada su importancia, es que la Interpretación del Patrimonio puede contribuir a una gestión adecuada del recurso que se interprete. $Y$ esta afirmación se fundamenta en dos aspectos:

1. La interpretación es y debe ser utilizado como instrumento para enseñar, educar con respecto a los distintos tratamientos y comportamientos que se deben tener en un sitio de características únicas y dadas sus cualidades, de extrema fragilidad, y así poder mostrar el camino para una perfecta conservación y respeto por nuestro único e irremplazable legado natural e histórico (fig. 19).

2. Utilizando la atracción de los distintos servicios interpretativos se puede influir, controlar y programar la distribución espacial del público de tal forma que la presión ocurra en zonas que puedan soportarla, y así desviar la atención de zonas frágiles, dispersando el flujo de visitas que pudieran alterar e incluso poner en peligro la existencia y perdurabilidad de las mismas (piénsese en el acertado ejemplo de la reproducción total de la Cueva de Altamira, en Santander).
Si bien podemos afirmar que la justificación existencial de la Interpretación del Patrimonio es el público, su principal objetivo es la conservación. Esto a su vez se descompone en otra serie de objetivos de carácter específico que, siguiendo a diversos autores (Guerra, 1998a, b y c; Guerra y Morales, 1987 y 1996; Morales, 1997 y 2001) se podrian resumir de la siguiente forma:

1. En relación al elemento interpretado:

- Identificar y conservar los valores de interés patrimonial

- Ordenar el flujo y las actividades de los visitantes

- Fomentar el uso adecuado del lugar

- aumentar la conciencia sobre la necesidad de su conservación.

2. En relación al visitante:

- Proporcionar recreación

- Aumentar la conciencia, el conocimiento y la comprensión del Patrimonio, tanto natural como cultural

- Impactar en el público y promover cambios actitudinales (fig. 20).

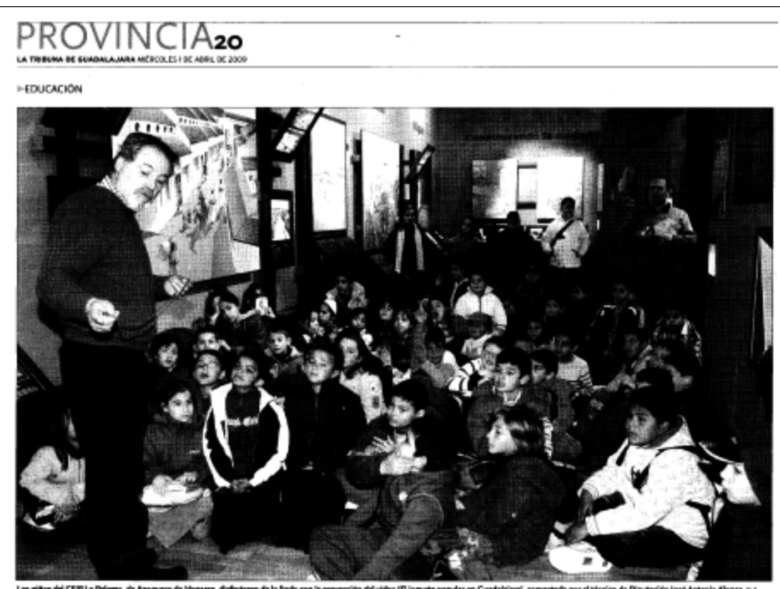

Aprender y disfrutar conociendo El pasado 26 de marzo daban comienzo las Rutas Educativas por la provincia que, con sus seis destinos
aderezados con animaciones teatrales, cuentos y talleres, llegarán este primer ano 52 centros de Cuadalajara

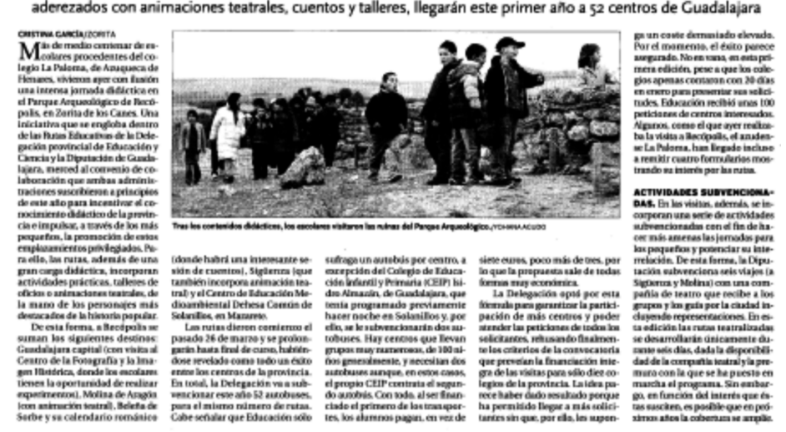

FIGURA 19. Reportaje sobre una actividad realizada en el PAR con motivo de las Rutas Educativas por la provincia de Guadalajara que se organizaban desde la Delegación de Educación, Ciencia y Cultura Provincial de Guadalajara. 


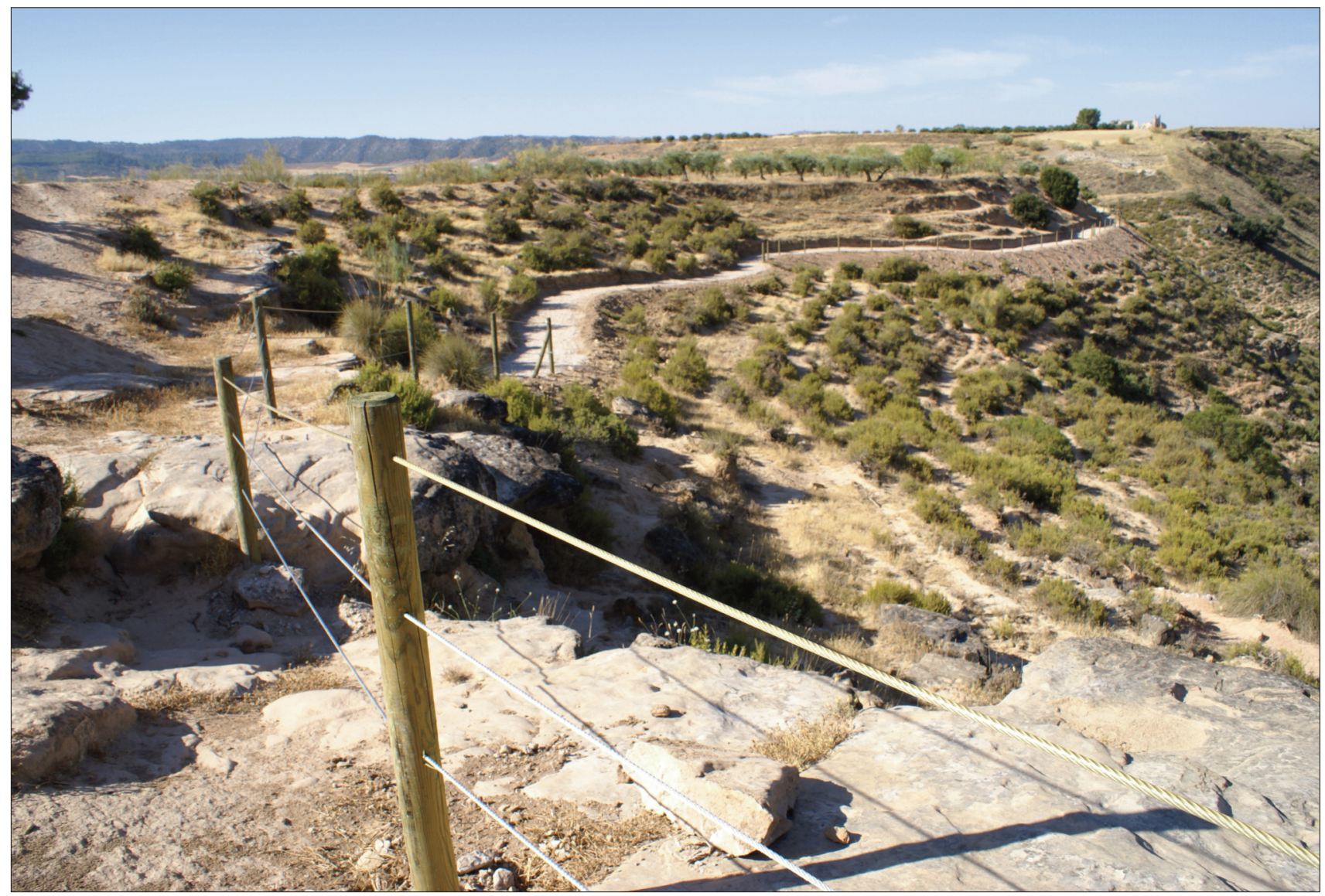

FIGURA 20. El PAR tiene marcados todos los itinerarios que pueden recorrer los visitantes para un buen uso y disfrute de la actividad, facilitando en la medida de lo posible el acceso y evitando cualquier tipo de riesgo para la integridad física de los usuarios así como para proteger y salvaguardar elementos frágiles del patrimonio visitado.

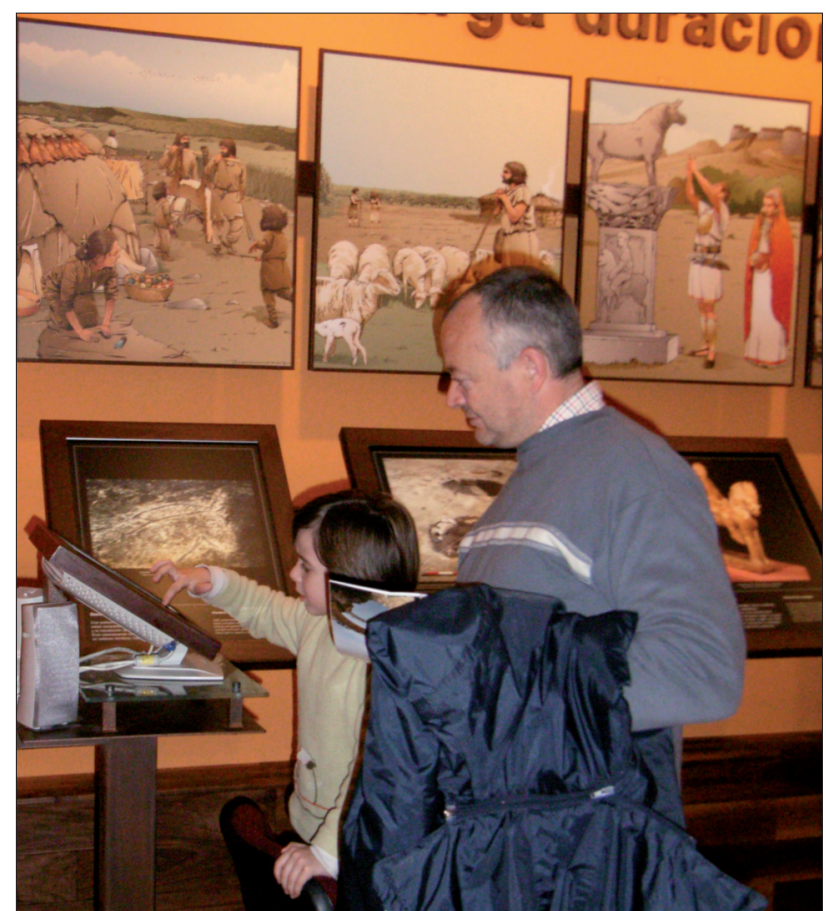

Figura 21. El público es general, pero no igual, y todos deben de ver satisfechas sus distintas necesidades culturales, luego el método debe ser particular.
El conjunto de principios que sirven de base para el desarrollo de la disciplina de Interpretación del Patrimonio, siguiendo a Tilden (1957) y a Guerra Rosado (1998) quedan resumidos de la siguiente manera:

La Interpretación debe relacionar los objetos de divulgación, rasgos interpretativos con aquello que se encuentra en la experiencia y la personalidad de aquellos a quienes va dirigida.

La información como tal no es interpretación. La IP es una forma de comunicación basada en la información, pero debe tratar además con significados, interrelaciones, implicaciones e interrogantes sobre ciertas cuestiones o materias.

La interpretación es un arte que combina muchas artes para explicar los temas presentados. Debe hacer uso de todos los sentidos para construir conceptos y conseguir reacciones en el individuo.

La interpretación es provocación; debe despertar la curiosidad, resaltando lo que en apariencia es insignificante.

La interpretación debe ser una presentación del todo y no de partes aisladas; los temas presentados deber estar interrelacionados dentro de un marco conceptual común.

La interpretación está dirigida al público general, pero debe tener en cuenta las características de cada tipo de público: niños/adultos, intereses, niveles de profundidad, etc. (fig. 21). 


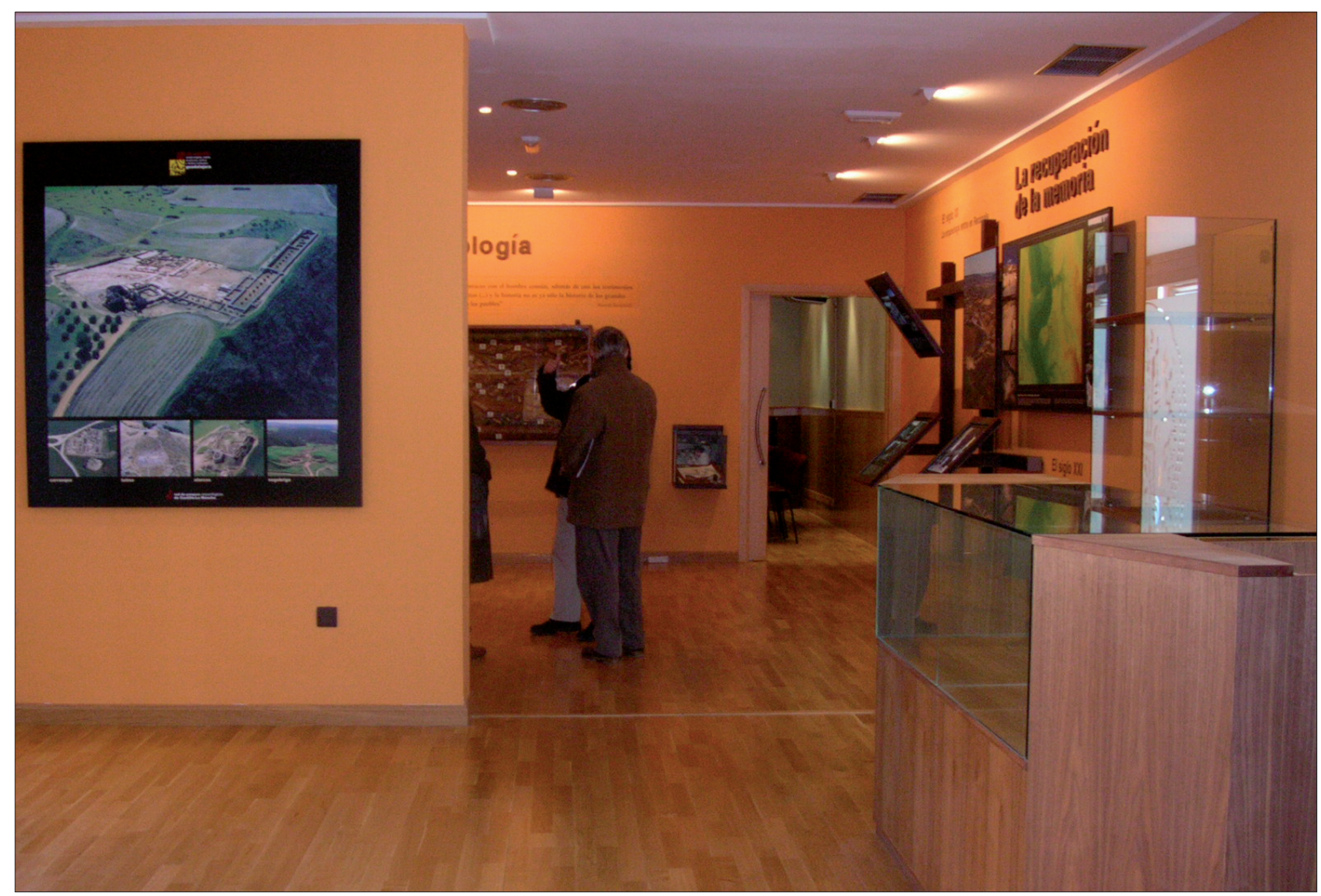

FIGURA 22. El Centro de Interpretación es lo primero que se encuentra el visitante a su llegada al PAR En el vestíbulo es recibido por el personal del PAR e informado de todos los aspectos relacionados con la visita, uso y disfrute de las instalaciones y recursos a visitar.

\section{LA HERRAMIENTA DE DIFUSION DEL PARQUE ARQUEOLÓGICO DE RECÓPOLIS: SU CENTRO DE INTERPRETACIÓN}

El Centro de Interpretación del PAR es un moderno edificio concebido como lugar de articulación de todos los aspectos relacionados con el Parque Arqueológico de Recópolis, siendo su principal función ser instrumento de divulgación cultural del Parque. Con la visita al Centro de Interpretación no sólo se hace un recorrido por las distintas etapas culturales que ha vivido este territorio, sino que a través de toda una serie de modernos y novedosos elementos museográficos, el visitante es capaz de capturar toda la información necesaria para poder interpretar y comprender los distintos restos arqueológicos que posteriormente visitará (fig. 22).

Este Centro de Interpretación se concibe como un órgano flexible en cuanto a la exposición de nuevos datos, pues siempre debe estar abierto y ser receptivo a los nuevos avances que la investigación científica puede aportar en cualquier momento. Es de vital importancia esta condición y cualidad para dar solución interpretativa y didáctica a todos y cada uno de los elementos que conforman el Parque Arqueológico, y asi tener «al día» cada uno de dichos elementos con las nue- vas teorias y conclusiones que puedan darse tras las investigaciones arqueológicas. Así mismo, no sólo los avances científicos tienen cabida en él, sino que también se deben valorar las propias necesidades que el propio público visitante demanda con respecto a lo expuesto, y adaptarse a las nuevas realidades socioculturales que la sociedad demanda en la actualidad para llenar sus espacios de ocio con conocimientos histórico-culturales. $Y$ es que dicho elemento del propio Parque, el Centro de Interpretación, es la herramienta principal de difusión y divulgación con la que cuenta el Parque Arqueológico para hacer posible la consecución de los objetivos últimos que está marcando el espíritu de la Ley de Parques Arqueológicos de Castilla-La Mancha (fig.23).

Todo el proyecto museográfico fue concebido con estas premisas de flexibilidad a la hora del material expositivo, con soluciones prácticas para facilitar, en un momento dado, los posibles cambios en las argumentaciones científicas, así como su posible enriquecimiento. Todo el proyecto se fundamenta en paneles didácticos que ilustran los diferentes contextos, usos y momentos históricos que se quieren mostrar. Dichos paneles están realizados con distintas técnicas que van desde fotos fijas, dibujos en $3 \mathrm{D}$, recreaciones pictóricas, cajas de luz con distintas planimetrías y reconstruc- 


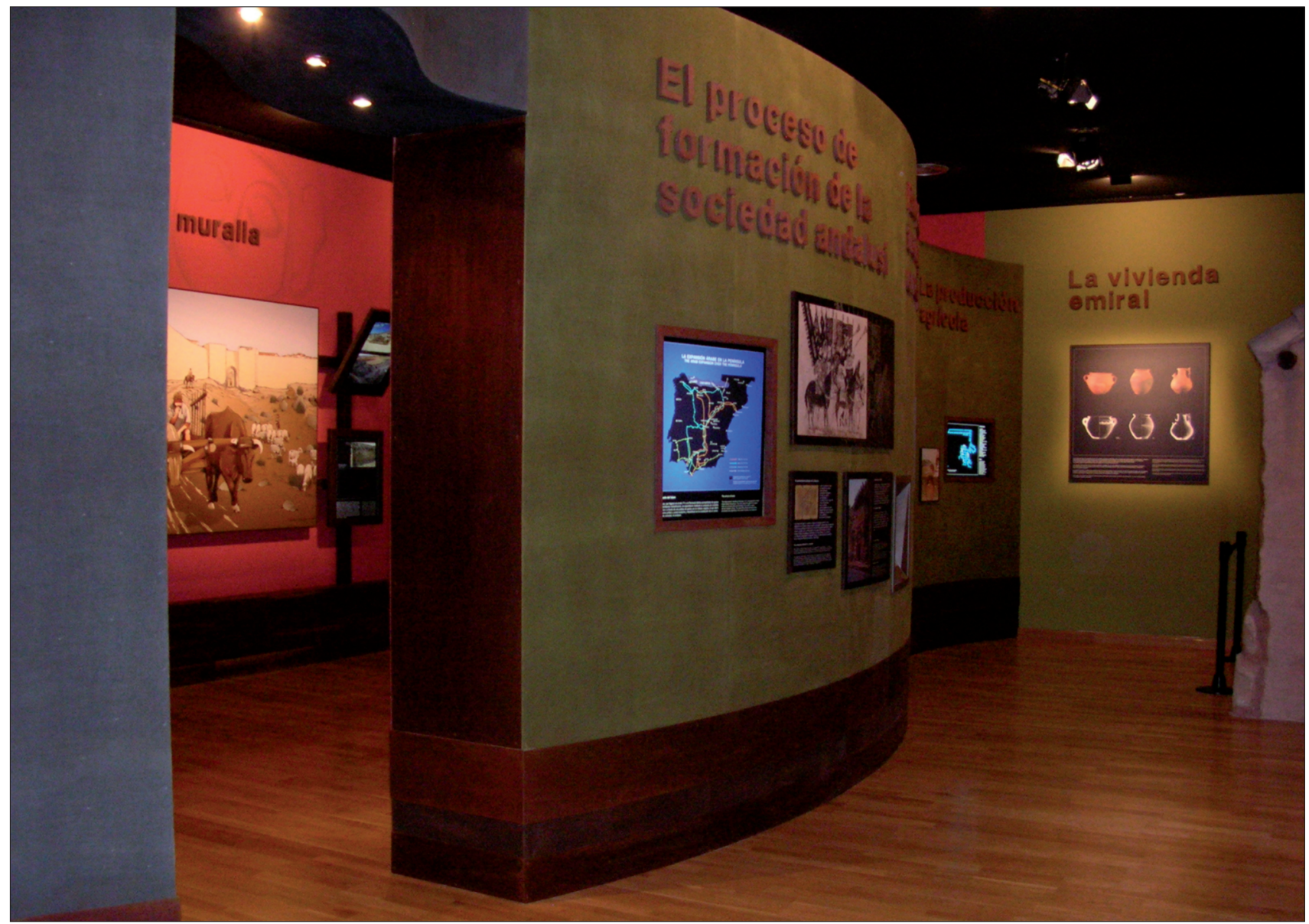

FiguRA 23: El diseño del centro de interpretación es lo suficientemente atractivo como para llamar y mantener la atención del público, sin embargo y lo que es muy importante, jamás se enmascara el mensaje histórico.

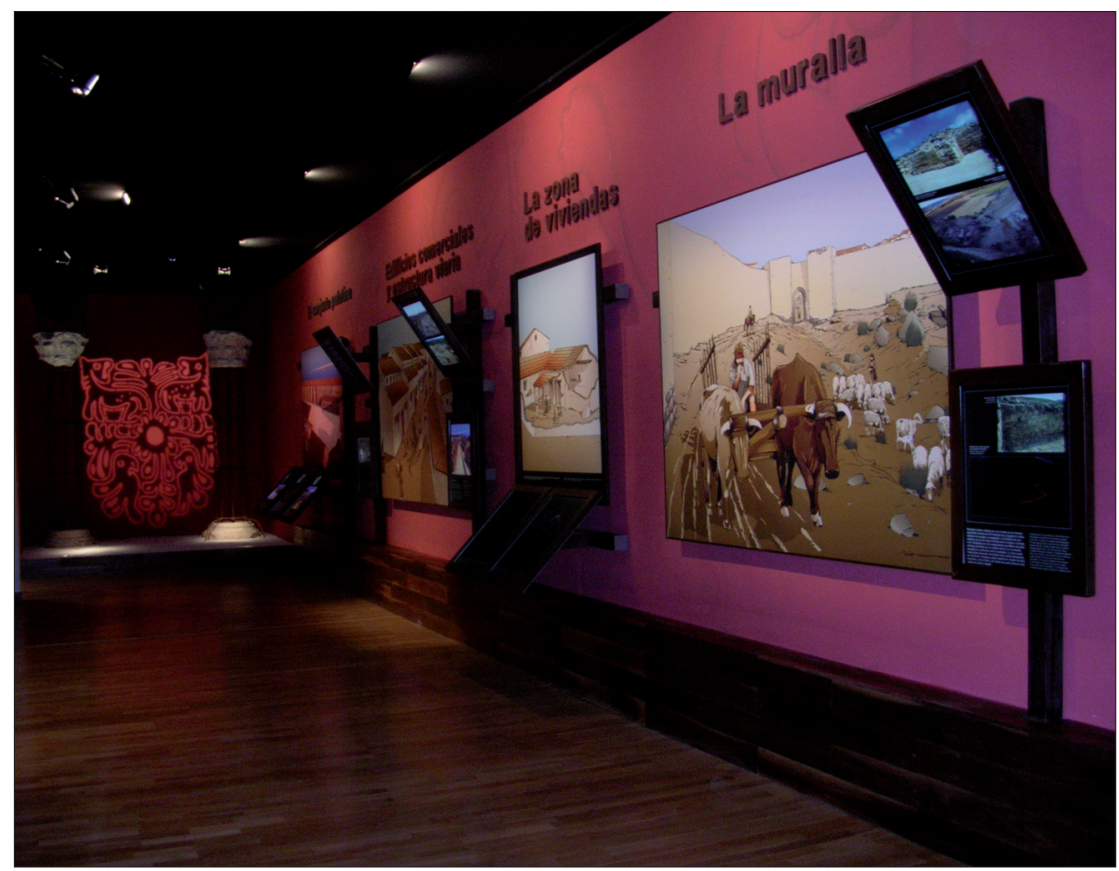

Figura 24. El Centro de Interpretación cuenta con 5 salas temáticas más un vestíbulo de atención al público y tienda de souvenirs relativos al PAR. Así mismo cuenta con una sala de audiovisuales donde se proyecta un documental del devenir histórico de este paisaje histórico. ciones, que de un lado no sólo resultan atractivas al público, sino que son de una fácil comprensión para todos los visitantes -indistintamente de su edad y conocimientos culturales más o menos especializados con respecto al tema-. Así mismo el montaje de dichos paneles es un montaje de fácil renovación, pues todo se basa en vinilos de fácil desmonte, y fácil producción. Todo pensado y proyectado desde el punto de vista de dar mayor flexibilidad y dinamismo en el discurso expositivo en función de los distintos avances científicos, así como los propios de puesta en valor de los distintos yacimientos y elementos que conforman el Parque Arqueológico (fig. 24).

A parte de esta cualidad didáctica e interpretativa (recreativa, inspiradora) para el público visitante; también es importante señalar cómo gracias al Centro se da el servicio de concentración del público y servir de preparación psicoló- 
gica entre el mundo cotidiano del visitante y el lugar que va a visitar, brindándole toda la información básica que va a necesitar en el desarrollo de su visita al parque arqueológico. Desde el propio Centro de Interpretación se van a encauzar y se van a desarrollar los itinerarios interpretativos por el yacimiento de Recópolis que en la actualidad se están ofertando al público visitante.

Teniendo en cuenta que la satisfacción de las necesidades básicas es un factor importante en la comodidad de las personas el Centro dispone, así mismo, de elementos adicionales como la existencia de áreas de descanso, tanto de interior como de exterior; servicio de tienda y de información; aseos y puntos de agua; así como papeleras distribuidas en número suficiente para mantener un buen funcionamiento y mantenimiento óptimo de recogida de limpieza y evitar que los residuos degraden el medio.

\section{ITINERARIOS INTERPRETATIVOS DEL PARQUE ARQUEOLÓGICO DE RECÓPOLIS}

Genéricamente se denominan itinerarios interpretativos a las rutas destinadas al público general que se desarrollan en un entorno determinado y en las que se interpretan o explican, con el apoyo de una serie de medios complementarios (guía interprete, carteles, folletos,...) los elementos que forman el espacio que se está visitando y sus distintas características y relaciones. La senda o el camino, se considerará como el equipamiento, el soporte físico; frente al concepto de "itinerario" que es el servicio que desde el Parque Arqueológico se está prestando para la Interpretación. Dichos itinerarios se formulan y se organizan desde el Centro de Interpretación.

Dentro de los distintos servicios que ofrece el Parque, los itinerarios son uno de los medios más efectivos puesto que se desarrolla en contacto directo con el recurso, en este caso el yacimiento de Recópolis, que se va a interpretar, constituyendo así una experiencia de primera mano entre el recurso y el visitante. Son itinerarios interpretativos de doble dualidad temática, pues de un lado explican la evolución cultural del territorio arrancando desde la fundación de la ciudad visigoda de Recópolis y su larga ocupación (ocho siglos, desde época visigoda hasta ya época tardo medieval), con todo un hilo conductor de los contenidos del mensaje que se fundamentan en un recorrido a través del tiempo que nos acerca a las sociedades visigoda que construyó y ocupó la ciudad de Recópolis, la sociedad andalusí habitó posteriormente y la última reocupación cristiana, sin olvidar nunca el medio ambiente y natural en el que se desarrolla esta historia cultural. Siempre y a lo largo de los diversos recorridos se llama la atención sobre los distintos hitos y referencias a cada fase cultural legibles en las distintas formas y estructuras arqueológicas que se conservan en la ciudad, así como a las diferentes formaciones geológicas, paisajísticas, elementos de flora y fauna que habitan y conforman el territorio.

\subsection{Itinerarios Interpretativos Autoguiados}

Esta ruta específica conduce al público a distintos puntos de interés que son explicados e interpretados mediante carteles bilingües en castellano e inglés. Las ventajas que se puede observar en los visitantes es la permisión de realizarse al propio ritmo que el visitante se quiera marcar; poseen disponibilidad permanente no sujeta al horario estricto del Parque y el único coste adicional que precisan es el mantenimiento; como medio de apoyo, los carteles está comprobado que provocan una mayor retención a corto plazo; las paradas son evidentes y de la duración que se estime oportuna; permiten ser leídos por varias personas a la vez. Como desventaja, pues obviamente atienden al punto señalado, luego toda cuestión circunstancial o dudas que surjan al visitante no pueden ser respondidas «in situ».

En los carteles se muestran ejemplos de planimetrias arqueológicas que dan la visión del cómo representan los
FiguRA 25. Ejemplo de cartel bilingüe en castellano e inglés de uno de los itinerarios interpretativos autoguiados por el PAR.

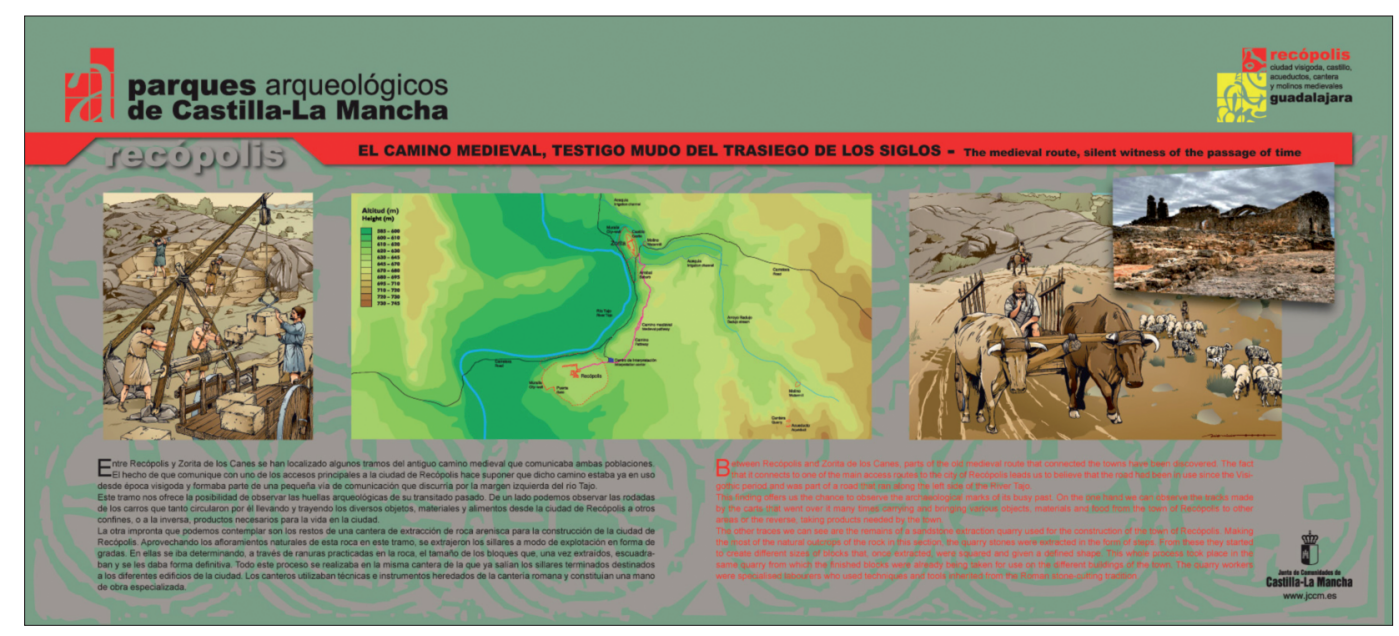


arqueólogos la realidad que el visitante contempla en el yacimiento; los dibujos interpretativos de esa realidad, es decir, las reconstrucciones ideales de los distintos elementos; y una breve y concisa explicación de lo que se contempla (fig. 25).

\section{2. Itinerarios Interpretativos Guiados}

En esta ruta el público, organizado en un grupo, es acompañado por un guía o intérprete del Centro de Interpretación. Este guía entrega de forma verbal la interpretación sobre los rasgos más sobresalientes del yacimiento al mismo tiempo que estimula al grupo a la participación y al uso de sus sentidos. El tamaño de los grupos es inferior a 30 personas puesto que se calcula que es un número ideal para garantizar la calidad de la experiencia. Así mismo, al tratarse de una actividad guiada, se puede adaptar la interpretación a las necesidades y características del grupo a la vez que se favorece el intercambio bilateral de información, contribuyendo todo ello a la efectividad de este medio interpretativo. Estos paseos guiados muestran como ventajas el contacto personal con un intérprete; la experiencia de primera mano con el recurso pudiendo utilizar todos los sentidos; se pueden aclarar dudas que surjan ipso facto; se adaptan al nivel de la concurrencia; permiten un control directo del uso del recurso por parte del público. Como desventajas, pues tenemos que, por ejemplo, la capacidad del guía influirá en la efectividad del itinerario; el visitante no puede ir a su propio ritmo; hay una limitación numérica en el grupo pro efectividad (no más de treinta personas).

Ambos tipos de itinerarios se completan con un folleto que se entrega en el Centro de Interpretación que, si bien son en algunos casos basura potencial; por regla general se convierten en un recuerdo de la experiencia y favorecen una mayor retención de conceptos aprehendidos a largo plazo.

\section{ITINERARIOS TEMÁTICOS DEL PARQUE ARQUEOLÓGICO DE RECÓPOLIS}

En el momento actual el PAR tiene dos recorridos temáticos: el itinerario temático sobre la ciudad visigoda de Recópolis y sus diferentes fases de ocupación a lo largo de la Historia; y el itinerario medioambiental "La Ruta del paisaje visigodo". En un futuro no se descarta ir incorporando nuevos elementos culturales con la creación de nuevos itinerarios en función de la visitabilidad de los otros yacimientos arqueológicos que componen el Parque. Con motivo extraordinario de Jornadas de Puertas Abiertas así como con motivo del Día Internacional de los Museos y tras la reciente consolidación de los paramentos del Castillo de Zorita gra- cias al 1\% Cultural, se han desarrollado algunas visitas guiadas a modo de prueba para la realización de un futuro itinerario a este elemento concibiéndose como un servicio guiado a corto plazo más del PAR que pueda ponerse en funcionamiento en cuanto el Castillo reúna unos mínimos para una visita óptima.

Lo mismo ocurrió hace dos años con la senda medioambiental, que tras varios meses de pruebas y proyecciones que dieran con una viabilidad de tránsito así como de guión interpretativo con unas pautas didácticas e hilo conductor que vinculase el territorio con los restos arqueológicos de una manera comprensible y articulada, se llevó a cabo la senda y el Observatorio de Aves, siendo inaugurado en el verano del año 2009 como un nuevo servicio al público del PAR.

\subsection{Itinerario temático del yacimiento arqueológico de Recópolis}

Este itinerario se organiza en torno a 18 puntos o paradas, desde donde se dan las interpretaciones necesarias de la ciudad de Recópolis con la contemplación real de lo que se está explicando (edificios comerciales y estructura viaria; la puerta monumental; la fortaleza andalusí; la iglesia palatina, etc. son algunos ejemplos de estas paradas). Tiene una distancia de recorrido que no supera los $2 \mathrm{~km}$, luego se presenta como un recorrido óptimo en función de la disponibilidad de tiempo y fuerzas de los distintos visitantes. La duración estimativa del recorrido interpretativo es de una hora aproximadamente. Y el sentido del mismo es bidireccional o circular -se empieza y se termina por el mismo sitio-. Si bien según las pautas que marca la experiencia en interpretación, lo más aconsejable son los itinerarios unidireccionales, no obstante por diversos motivos intrínsecos al propio yacimiento de Recópolis y sus circunstancias actuales, se convino que en este caso lo más óptimo fuera la bidireccionalidad. En este circuito cerrado de ambos sentidos el guía interprete o la papelería -en función de la elección del visitante a la hora de hacer su recorrido, o acompañado de un guía o autoguiado- conduce al público visitante a través de los restos visigodos de la ciudad, interpretando primero la ciudad visigoda, para luego, posteriormente y desandando lo andado, el informador cultural o interprete señala y da importancia a distintos elementos reflejos de otras épocas vividas en Recópolis reconduciendo la mirada a puntos concretos que, de una forma natural y cotidiana, hace entendible las distintas ocupaciones y fases históricas que vivió la ciudad de Recópolis que tan difíciles y áridas son de transmitir. De este modo los visitantes comprenden a la perfección el dinamismo con el que se vivió en Recópolis y cómo los muros son testigos elocuentes de ello. 


\subsection{Itinerario temático medioambiental "La Ruta del Paisaje Visigodo" y el Observatorio de Aves}

En esta ocasión se recorre una senda unidireccional 1,5 $\mathrm{km}$. que bordea una ladera cuyas vistas sobre el Tajo son dignas de ser contempladas por su belleza, así como interesante punto estratégico de observación de la avifauna que lo habita gracias al Observatorio de Aves que sobre el se ha construido. Desde este recorrido se pueden contemplar los diferentes ecosistemas que confluyen en este mismo punto y aprender sus diferencias: bosque de rivera; monte bajo; montes yesíferos; sierras; etc. Se muestran conceptos tanto de geología, como de flora y fauna, así como su uso histórico, tradicional e incluso actual. Se articula entorno a cinco paradas en donde se hace hincapié en los siguientes temas:

1. Panel introductorio que lleva por título «Mira a tu alrededor" y con el que se trata de dar una visión global del territorio y los diferentes ecosistemas que lo componen y cómo gracias a estas diferencias los hombres y mujeres del pasado pudieron basar su economía desde un punto de vista sostenible. Así mismo se analizan las diferencias en su evolución a lo largo de los siglos enlazándolo con los usos actuales de los recursos medioambientales.
2. El Río Tajo. Se plantea el río como columna vertebral del territorio histórico que lo ha caracteriza no sólo desde el punto de vista medioambiental sino históricocultural. En este punto se hace referencia y se explica este espacio protegido denominado Reserva Fluvial "Sotos del río Tajo». Este punto está ubicado exactamente en el observatorio de aves, un mirador volado sobre el río que facilita la visión de este territorio histórico desde todos los ángulos. Así mismo es un lugar privilegiado para la observación de todas las aves acuáticas que habitan en este tramo del río -garzas, somormujos, patos, etc.- así como las rapaces que se alimentan en él -águilas, halcones, etc.-. Se han adquirido prismáticos para que los visitantes puedan observar a estas aves in situ (fig. 26).

3. Variación cromática. Aprovechando una buena perspectiva de los cerros margosos de Pastrana y Yebra se hace una introducción a la geomorfología que caracteriza todo el territorio, donde dominan formaciones geológicas formadas por calizas y margas que configuran este espacio de un modo muy especial.

4. El Camino Medieval, testigo mudo del trasiego de los siglos. Se observan las rodadas que dejaron los carros grabadas en la roca arenisca de recorrer el camino desde Recópolis a Zorita. Así mismo se observan

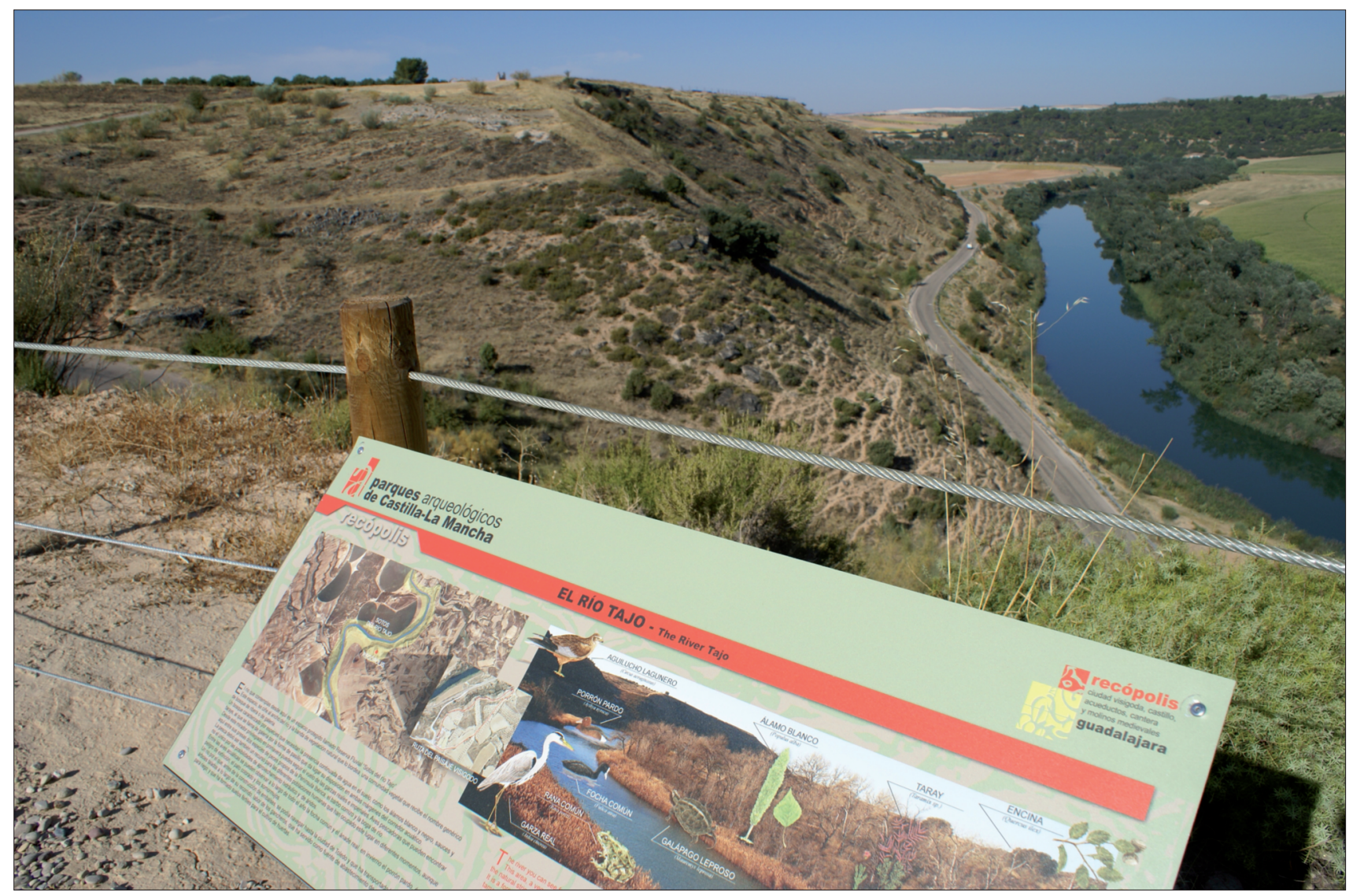

FiguRA 26. Recópolis de fondo y la arteria principal de este paisaje histórico: el Río Tajo. 


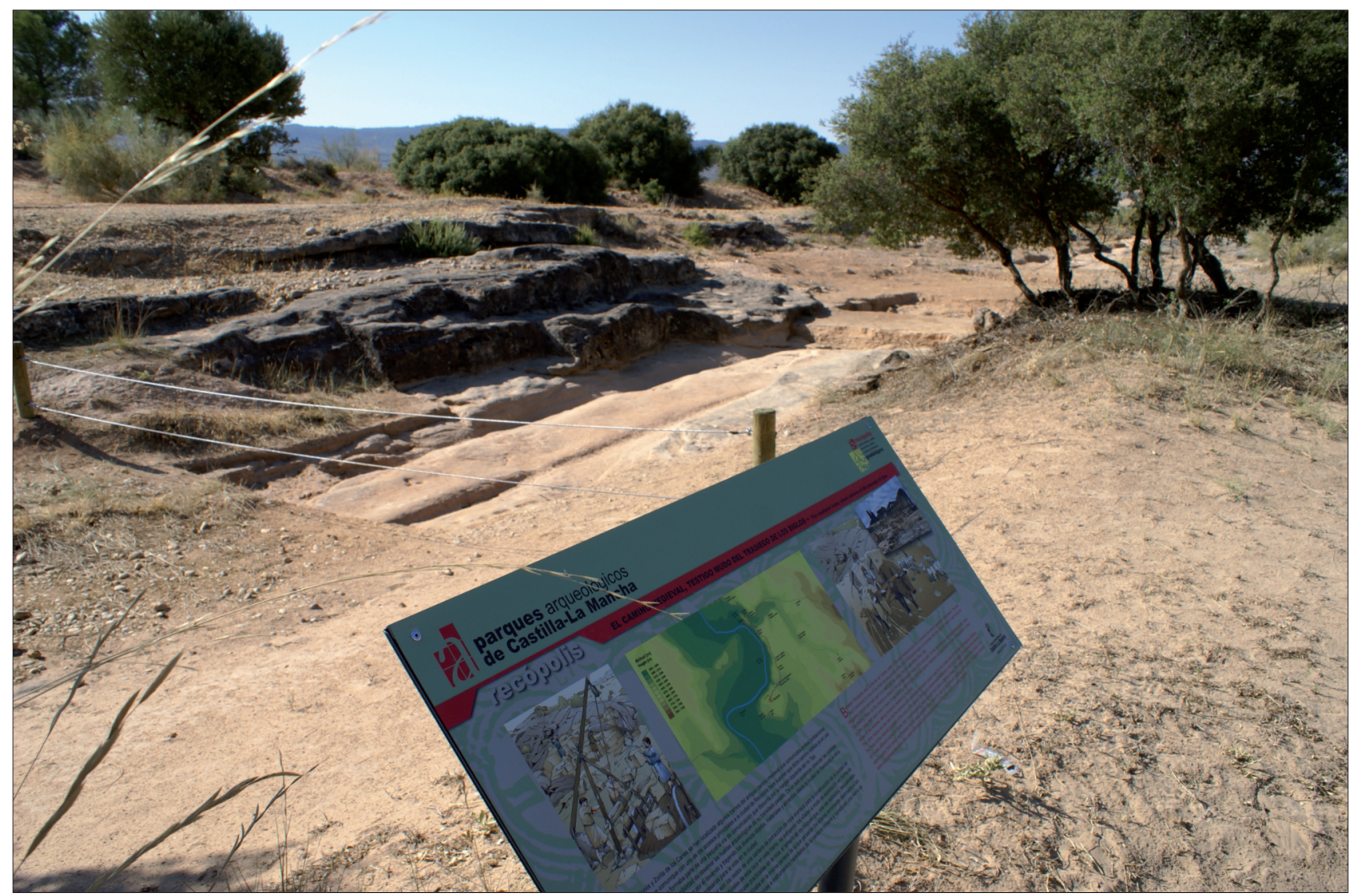

FiguRA 27. Detalle del Camino Medieval.

restos de las canteras de donde los visigodos extrajeron los grandes sillares con los que construyeron la ciudad de Recópolis (fig. 27).

5. Protagonistas las aves. Con la Sierra de Altamira de telón de fondo, se brinda la oportunidad al visitante no sólo de entender este ecosistema y sus particularidades, sino de acercarse de lleno al conocimiento de las rapaces que en él habitan, así como de conocer otra fauna como el jabalí, corzo y ciervo que han sido objeto de caza desde los primeros pobladores de la zona.

\section{EL PARQUE ARQUEOLÓGICO DE RECÓPOLIS Y SU REPERCUSIÓN ECONÓMICO-SOCIAL EN LA ZONA}

Considerando que el Parque Arqueológico de Recópolis aún se encuentra en un estadio incipiente para considerarlo un fuerte motor económico y constatar la proyección socioeconómica en la comarca como elemento revulsivo de un desarrollo sostenible, si es cierto que se puede empezar a afirmar que desde la inauguración del Parque Arqueológico de Recópolis en noviembre de 2005 las cosas van cambiando bastante en la zona en la que se ubica. Ya en estos cinco años de andadura se empiezan a comprobar ciertas realidades que empiezan a ser llamativas dentro del entorno profundamente rural y que sufre graves problemas de despoblación, siendo la que resta bien de edades avanzadas, así como de niveles culturales bajos con poco grado de profesionalización. Esta población ya empieza a creer en el PAR y esto hace que empiece a existir una progresiva implantación cultural, social y económica de esta realidad que es el PAR.

Ya son más de 65.000 visitantes los que han recorrido el PAR y por ende, han conocido la zona y disfrutado de ella en todas sus vertientes. La consolidación de la demanda ha dado lugar a la ampliación de oferta del Parque Arqueológico, que presenta buen número de actividades de nueva creación, como es el caso del itinerario medioambiental y del observatorio de aves, creados y puestos en marcha el año 2009.

A todo esto hay que añadir que se han creado 5 puestos de trabajo directos en el propio Parque Arqueológico. Así mismo se cuenta con diversas empresas de la zona que ofrecen servicios puntuales de mantenimiento, limpieza, jardinería, etc., lo que fomenta el desarrollo e iniciativas de autoempleo en la zona (fig. 28).

También es interesante hacer mención que durante varios años (2007, 2008 y 2009) el PAR ha contado con Talleres de Empleo cuyo número de empleos anualmente sumaba otras 20-25 personas más. Personas que además no tenían 


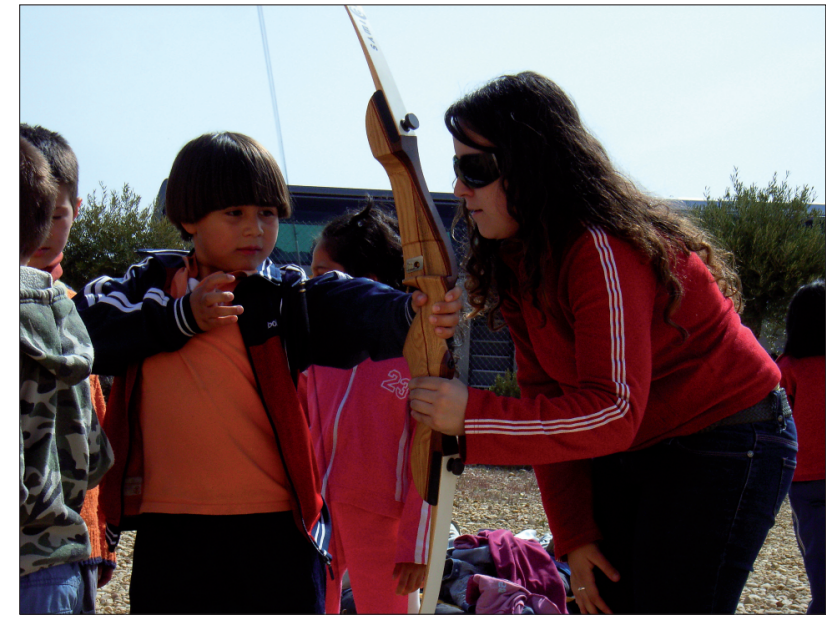

Figura 28. Equipo Deportivo de Tiro con Arco de Almonacid de Zorita mostrando en el PAR a un grupo de escolares cómo era la caza en época medieval.

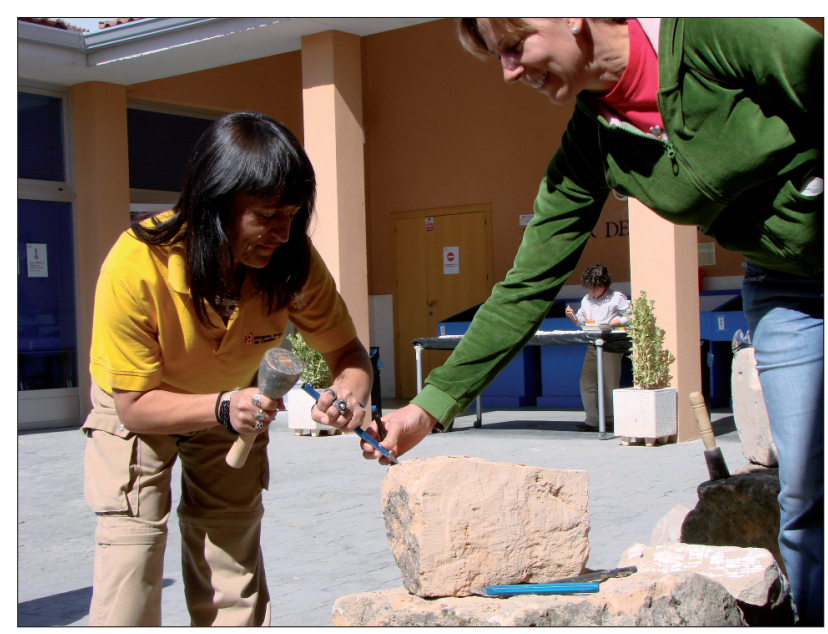

FIgURA 29. Monitora del Taller de Empleo Recópolis II, del módulo de cantería, instruyendo a una trabajadora del PAR con técnicas de talla en piedra.

cualificación profesional y que durante su relación contractual con el PAR disfrutaron de contratos laborales que a su vez les estaban formando dentro de diferentes oficios - cantería, albañilería e informadores turísticos (fig. 29).

A esto hay que unir la ocupación temporal durante 6 meses gracias a los planes de Inserción Laboral que ofrece en SEPECAM en colaboración con la Consejería de Educación, Ciencia y Cultura y que facilitan el personal necesario para desarrollar las campañas sistemáticas de excavación arqueológica del propio yacimiento (contando con un número de 30 personas) más 4 personas que mediante dichos planes de inserción laboral constituyen personal de refuerzo en los meses de temporada alta para las instalaciones y Centro de Interpretación. Haciendo números y comparativas podemos afirmar que anualmente el PAR tiene una producción de trabajo directo nada desdeñable siendo considerado en la zona la «mayor empresa empleadora» (fig. 30).

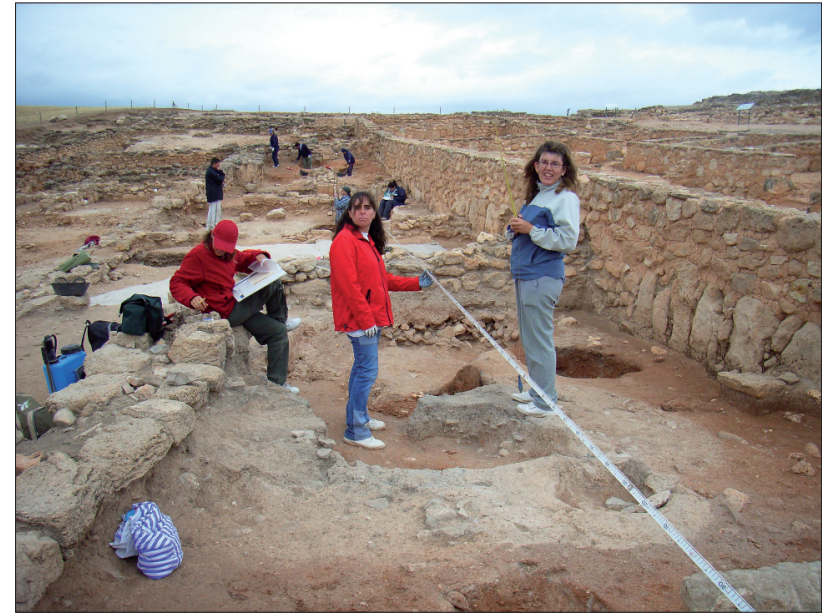

FIGURA 30. Campaña de excavaciones sistemáticas en el yacimiento de Recópolis.

Desde un punto de vista indirecto, en los pueblos del entorno del PAR se ha detectado un incremento en el número de establecimientos de hostelería y hospedería. La influencia del Parque Arqueológico se deja sentir también en la activación de otros recursos culturales y naturales del entorno que son visitados.

\section{CONCLUSIONES}

El espíritu de la Ley de Parques Arqueológicos de CastiIla La Mancha tiene como principales objetivos la investigación, divulgación y conservación del Patrimonio Natural y Cultural de un espacio concreto. Para la consecución de tales objetivos los Parques Arqueológicos de Castilla-La Mancha disponen de modernos centros de interpretación que articulan todo su funcionamiento constituyéndose en las herramientas principales de las que dispone la Red de Parques de Castilla-La Mancha en las labores de divulgación mediante la interpretación de los diversos elementos culturales y medioambientales que conforman cada uno de los Parques Arqueológicos (fig. 31).

El Centro de Interpretación del Parque Arqueológico de Recópolis ha sido diseñado pensando en el público potencial y en la prestación de los servicios necesarios que dicho público en un momento dado demanda para cubrir las distintas expectativas que ha generado con respecto a su visita al Parque Arqueológico. Así mismo, funciona en la actualidad dentro de los parámetros teóricos que nos brinda la joven disciplina de la Interpretación del Patrimonio. Disciplina que no sólo se ocupa de estudiar los medios y las distintas técnicas con las que poder transmitir y comunicar la esencia de los elementos patrimoniales determinados que pueda contemplar un visitante; sino que estudia las distintas reacciones de éstos con respecto a la transmisión de este tipo de informaciones y a sus mo- 


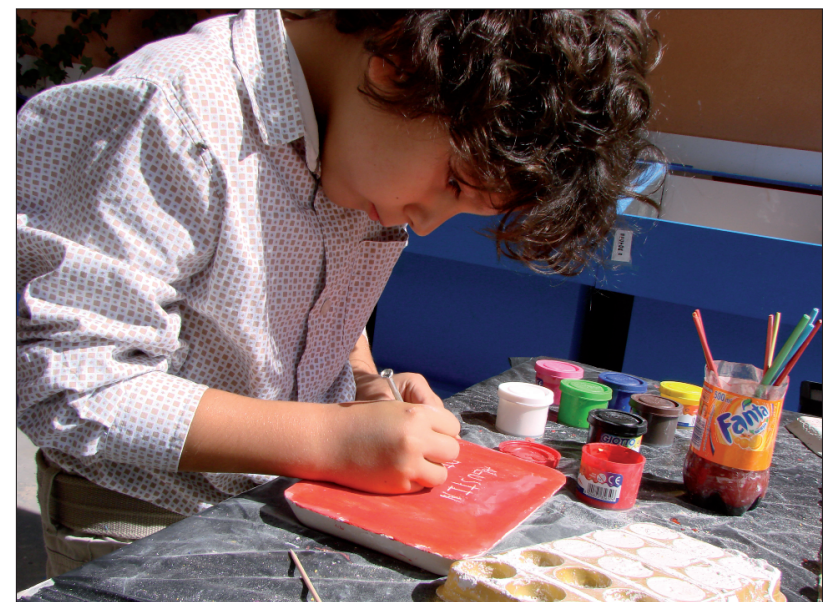

FigURA 31. El desarrollo de actividades y talleres arqueológicos adaptados a escolares no sólo fomentan la visita al PAR, sino que ofrecen enormes posibilidades a la hora de la transmisión de diversos conocimientos relacionados con los propios curricula y planes de estudio escolares.

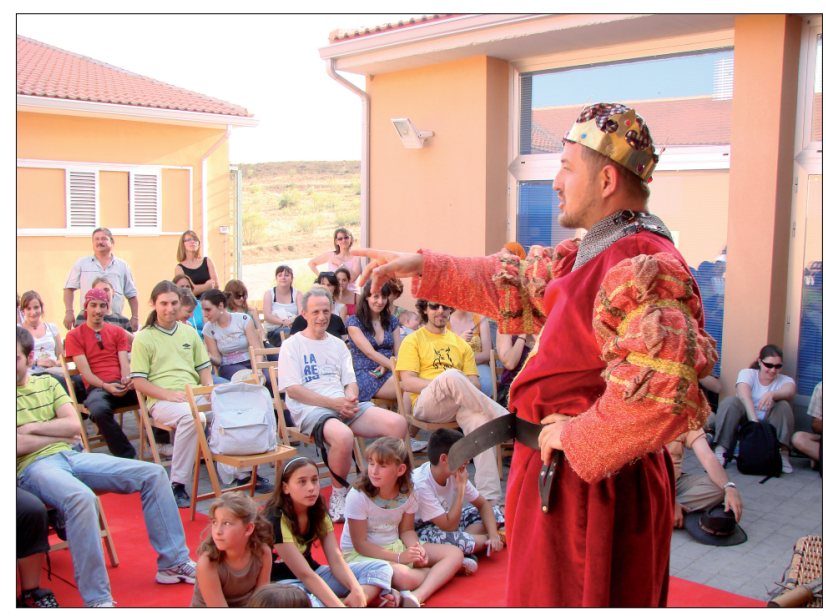

FIgURA 32. Representación teatral de "La Reina sin Nombre", novela contextualizada en época visigoda por su autor y representada por Galápagos Teatro Cálido en el PAR.

dos, para comprobar su total o nula efectividad en la recepción del mensaje a transmitir. $Y$ todo con un objetivo común a la propia gestión y razón de ser del Parque Arqueológico: la conservación del Patrimonio, entendiéndose este tanto en términos culturales como naturales (fig. 32).

Desde la perspectiva dinámica que nos brinda tanto las distintas excavaciones sistemáticas que se realizan en el Parque Arqueológico, así como los gustos cambiantes de la sociedad en general, siempre siguiendo la línea de la superación; el Centro de Interpretación se concibe como un espacio abierto y flexible en donde cada nuevo elemento, teoría, idea o necesidad, deben de ocupar su espacio y tener su respuesta.

La puesta en marcha de la Red de Parques Arqueológicos de Castilla-La Mancha ha supuesto un gran esfuerzo para la Comunidad Autónoma, no sólo económico, sino también jurídico y de gestión. Sin embargo, todo este esfuerzo y según se constata por la experiencia y las estadísticas, ha merecido la pena y ya ha empezado a dar sus frutos, pues los Parques Arqueológicos han sido totalmente aceptados por la sociedad.

Y teniendo presente que el Parque Arqueológico de Recópolis es todavía una institución joven, poco consolidada y sobretodo, poco divulgada, podemos afirmar que el número de visitantes supera con creces las expectativas más optimistas.

En todo esto hay que destacar la reversión social que implica este proyecto que devuelve de alguna manera la inversión económica y científica que se emplea en el patrimonio arqueológico.

Por otro lado hay que ser conscientes que la implantación social es fundamental para una buena valoración del patrimonio arqueológico, pero también para su asunción como recurso generador de riqueza en equilibrio con la necesidad de su conservación y protección.

El camino andado es corto, y queda mucho aún por recorrer. Es costoso en muchos sentidos, pero desde luego que todo el esfuerzo invertido en este proyecto y en toda la Red de Parques Arqueológicos de Castilla-La Mancha redunda en no pocos beneficios, no sólo desde el punto de vista estéticocontemplativo e histórico-científico; sino socio-económico haciendo cada día más patente que los Parques Arqueológicos son motores económicos de las zonas en las que se ubican dentro de un marco de desarrollo sostenible (fig. 33).

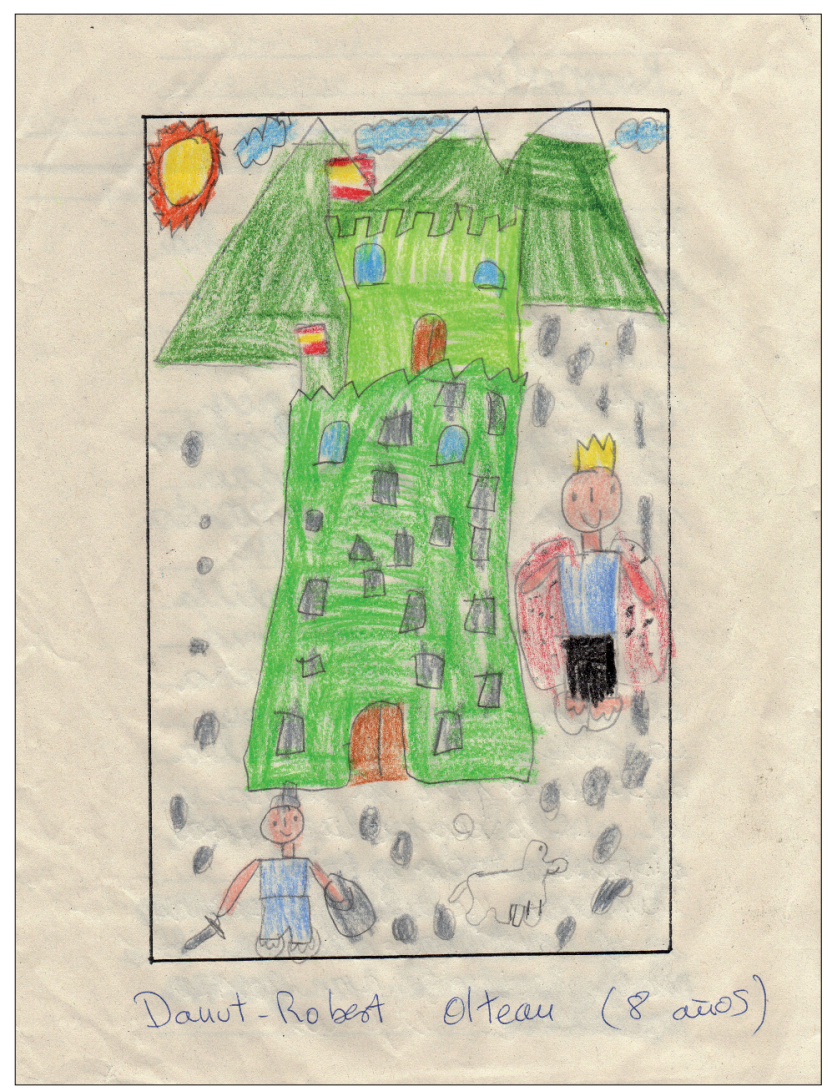

FIGURA 33. Dibujo interpretativo de cómo sería la ciudad visigoda de Recópolis en tiempos de su fundador Leovigildo, realizado por un joven escolar tras su visita al PAR. 


\section{BIBLIOGRAFÍA}

BINKS, G.; DYKE, J. y DAGNALL, P., 1988: Visitors Welcome. A manual on the presentation and interpretation of archeological excavations. English Heritage.

Catálogo Regional de Especies Amenazadas de Castilla-La Mancha (Decreto 33/1998)

Declaración de Microreserva de los Cerros Margosos de Pastrana y Yebra (Decreto 70/2002 del 14 de mayo).

Declaración del Parque Arqueológico de Recópolis (Decreto 280/2004, de 30-11-2004).

Declaración de Reserva Fluvial de los Sotos del Río Tajo (Decreto 288/2008 de 7 octubre de 2003).

De Juan Garcia, A. 2004: "Escuelas Taller y Patrimonio Histórico». En I Congreso de Patrimonio Histórico de Castilla-La Mancha. Tomo I. UNED: 79-99.

- et al. 2006: «El valor didáctico del Patrimonio: los Parques Arqueológicos. La experiencia del Parque Arqueológico de Alarcos-Calatravan. En Idea-La Mancha: 240-246.

- 2007: "Parque Arqueológico de Alarcos-Calatrava. Difusión y Gestión del Patrimonio Arqueológico en Castilla La Manchan. En Arqueología de Castilla-La Mancha. Cuenca: 331-354.

De Juan Garcia, A. y Gómez Rodado, J. 2005: «Un proyecto de empleo y formación para el patrimonio arqueológicon. Boletín del Instituto Andaluz del Patrimonio Histórico. 54: 113-115

GueRRA, F. J., 1998: «Espacios Naturales Protegidos y Educación Ambiental». Andalucía Ecológica 1.

- 1998: "La Interpretación: una herramienta para conocer el Patrimonion. Andalucía Ecológica 2.

- 1998: "La Importancia de sentir nuestro entorno". Andalucía Ecológica 4.
GuerRA, F. J. y Morales, J., 1987: «Estudio sobre los Equipamientos Educativos en los ENP españoles». Informe preparado para las Segundas Jornadas de Educación Ambiental, Valsaín, Segovia.

- 1996: "La atención a los visitantes de los Espacios Naturales Protegidos". En Seminarios permanentes de Educación Ambiental. Monografias del Ministerio de Medio Ambiente. Centro de Publicaciones. SGT.

Ley de Parques Arqueológicos de Castilla-La Mancha (Ley 4/2001, de 10-05-2001).

LORENTE, E. et al., 2006: «La Red de Parques Arqueológicos de Castilla-La Manchan. En IV Congreso Internacional sobre musealización de Xacementos Arqueológicos. Santiago de Compostela. Xunta de Galicia: 133-152.

MorALES, J., 1983: «La Interpretación Ambiental y la Gestión del Medio». Comunicaciones y Ponencias de las I Jornadas de Educación Ambiental, Sitges, Barcelona.

- 2001: Guía Práctica para la Interpretación del Patrimonio. Madrid. Consejería de Cultura. Junta Andalucia/TRAGSA.

Olmo Enciso, L., 1985: "La Iglesia del Castillo de Zorita de los Canes». En Wad-al-Hayara, 12: 97-109.

- et al., 2003: «Recópolis: investigaciones arqueológicas en los años 2001 y 2002». En ABAD CASAL, L. et al: Investigaciones Arqueológicas en Castilla-La Mancha (1996-2002). Toledo. Junta de Comunidades de Castilla-La Mancha, Servicio de Publicaciones: 325-343.

- 2006: Recópolis, un paseo por la ciudad visigoda, catálogo de la exposición, Madrid.

- (Ed.), 2008: Recópolis y la ciudad en la época visigoda, Zona Arqueológica 9.

- et al., 2008: Recópolis: Guía del Parque Arqueológico. Toledo, Junta de Comunidades de Castilla-La Mancha (Ed.). 
